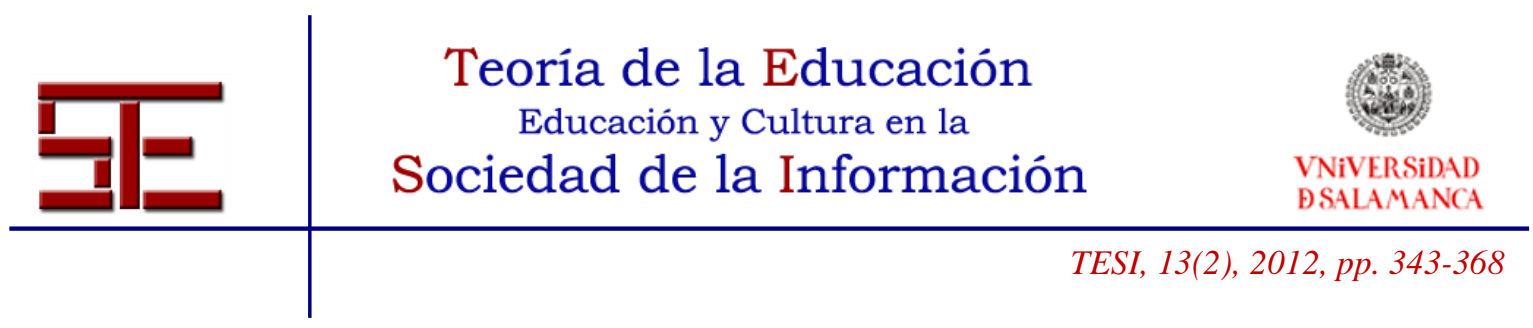

\title{
PRIMEROS RESULTADOS DE LA APLICACIÓN Y EVALUACIÓN DE UN PROGRAMA DE EDUCACIÓN PARENTAL: "CONSTRUIR LOCOTIDIANO"
}

Resumen: En este trabajo se presentan los primeros resultados obtenidos en la aplicación y evaluación de un programa de educación parental, "Construir lo cotidiano", puesto en marcha durante el presente curso académico en cuatro centros educativos en los niveles de Educación Infantil y Primaria del Principado de Asturias. En el estudio participan 34 madres y padres (16 parejas de familias nucleares y dos familias monoparentales). La implementación del programa no ha estado exenta de dificultades, en especial, la captación de familias ante el requisito de la presencia voluntaria de ambos miembros de la pareja. Los resultados de la evaluación ponen de manifiesto efectos positivos de la intervención en las familias participantes, observándose cambios a corto plazo tanto en las actitudes, preferencias y creencias que la familia posee sobre los roles sexuales, como en el comportamiento respecto al reparto del trabajo doméstico (tareas del hogar, cuidado de los hijos e hijas y trabajo emocional) que han permitido el buen funcionamiento familiar, a la vez que se ha potenciado la colaboración familiar enseñando a niños y niñas a participar en dichas responsabilidades. Se presentarán y discutirán datos de la parte del postest relativa al grado de satisfacción y utilidad del programa.

Palabras clave: corresponsabilidad familiar; educación familiar; estudio piloto; programa de educación parental; evaluación de programas; conciliación de la vida laboral y familiar.

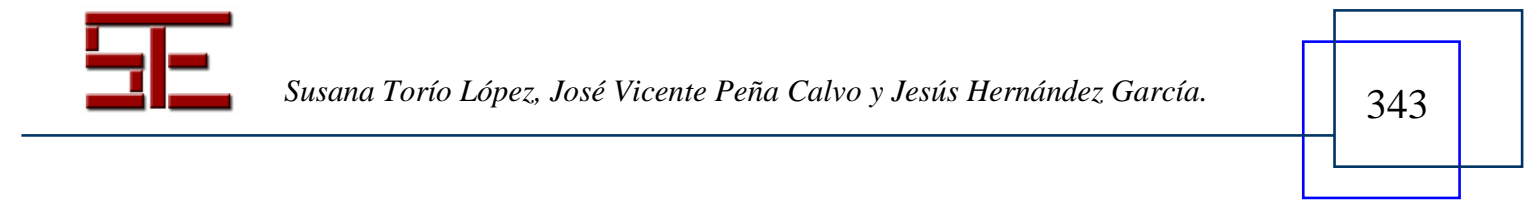




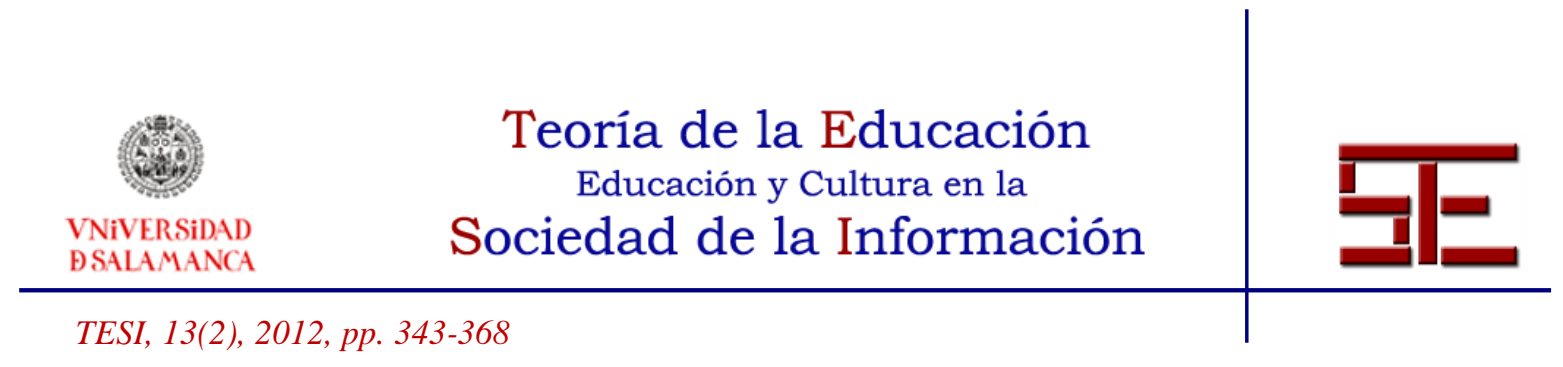

\title{
"BUILDING DAILY LIFE" PARENTAL EDUCATION PROGRAM: FIRST RESULTS OF ITS IMPLEMENTATION AND EVALUATION
}

\begin{abstract}
In this paper, firs results of the implementation and evaluation of a parental education program are presented. "Building daily life" parental education program, has been developed in four Preschool and Primary schools in the Principality of Asturias, during the current academic year. 32 parents have participated in it (15 nuclear families and 2 one-parent families). Its implementation has not been easy as it was condition sine qua non that the two members of the couple assisted to it. Evaluation results show the positive effects of the program in families' attitudes, preferences and beliefs about gender roles and housework (traditional housework, childcare and emotional work). The program has also increased families' cooperation and children participation in family responsibilities. To sum up, we will present some evaluation results about satisfaction and usefulness of the program.
\end{abstract}

Keywords: Family co-responsability; family education; exploratory testing; parental education program; evaluation of programs; family and work conciliation.

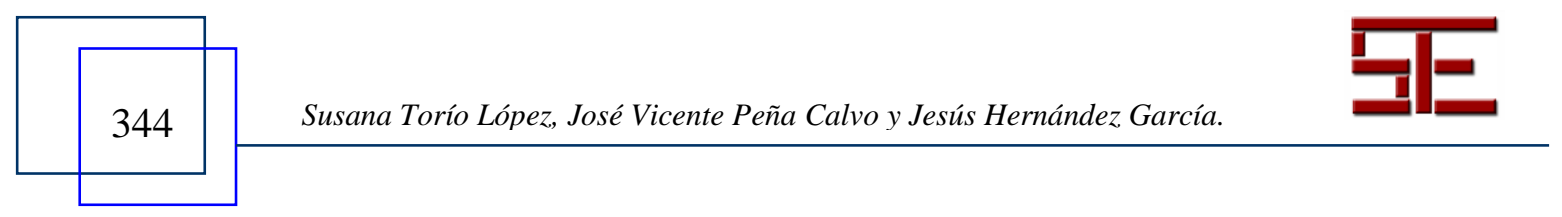




\begin{tabular}{c|cc} 
Teoria de la Educación \\
Educación y Cultura en la \\
Sociedad de la Información
\end{tabular}

\section{PRIMEROS RESULTADOS DE LA APLICACIÓN Y EVALUACIÓN DE UN PROGRAMA DE EDUCACIÓN PARENTAL: "CONSTRUIR LO COTIDIANO"}

Fecha de recepción: 20/09/2011; fecha de aceptación: 20/10/2011; fecha de publicación: 26/07/2012

Susana Torío López

storio@uniovi.es

Universidad de Oviedo

José Vicente Peña Calvo

vipe@uniovi.es

Universidad de Oviedo

Jesús Hernández García

ihdz@uniovi.es

Universidad de Oviedo

\section{1.- INTRODUCCIÓN: PROCESO DE EVALUACIÓN Y MEJORA DEL PROGRAMA DE EDUCACIÓN PARENTAL "CONSTRUIR LO COTIDIANO"}

El programa de educación parental "Construir lo cotidiano" ${ }^{1}$, dirigido a madres y padres con hijas e hijos de Educación Infantil y Primaria, elaborado por miembros del grupo de investigación ASOCED, pretende revisar la dinámica familiar y reconstruir el marco de relaciones familiares, de división de las tareas y de redistribución de responsabilidades (tareas del hogar, cuidado de los hijos e hijas y trabajo emocional), de manera que fomenten en los hijos e hijas hábitos de igualdad, solidaridad y responsabilidad compartida. Nos situamos en un programa de formación de madres y

\footnotetext{
1 Programa elaborado por el Grupo de Investigación ASOCED (Área de Teoría e Historia de la Educación de la Universidad de Oviedo) y financiado por el Plan Regional de Investigación del Principado de Asturias dentro del Proyecto de Investigación de Perspectiva de Género de la convocatoria del año 2007 de título "Corresponsabilidad familiar: diagnóstico de situación, elaboración e implementación de un programa para el cambio de roles" (referencia PG07-01). Para un conocimiento más exhaustivo del mismo ver; Torío López, S., Peña Calvo, J.V., Rodríguez Menéndez, M.C., Fernández García, C.M. \& Molina Martín, S. (2010. Hacia la corresponsabilidad familiar: "Construir lo cotidiano. Un programa de educación parental". Educatio Siglo XXI, 28(1), 85-108.
}

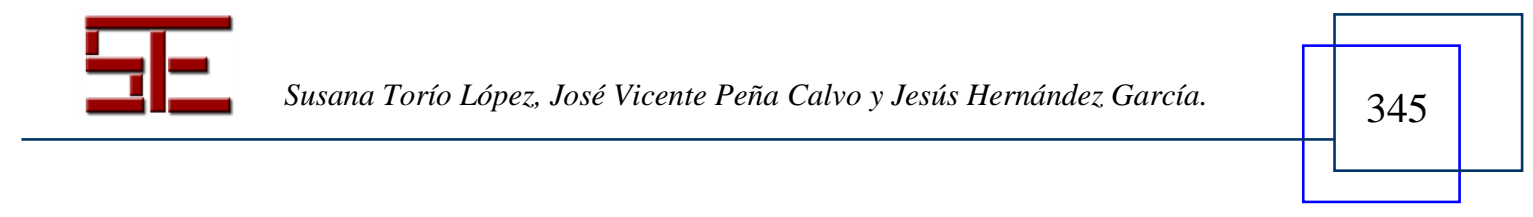




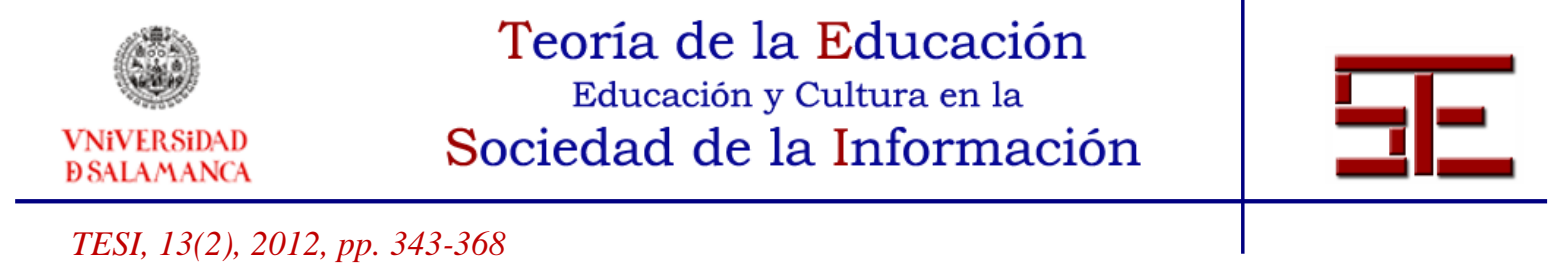

padres de tipo "experiencial" que tiene como objetivo primordial conceptualizar las prácticas de la vida cotidiana. A diferencia de otros, trata de abordar la formación de padres y madres en sus relaciones personales comunitarias en un período relativamente más tranquilo que el de la adolescencia, en el que todo resulta más complicado; pues en ésta las prácticas educativas están más asentadas y las rutinas lo pueblan todo. No quiere ser una recopilación de recetas, sino de ideas, y cada familia, con su experiencia, las concretará en cada momento con las respuestas adecuadas.

En el curso académico 2009/2010 se llevó a cabo la aplicación del programa en cuatro centros educativos en los niveles de Educación Infantil y Primaria del Principado de Asturias para su evaluación y validación -dos centros públicos y dos concertados de la zona central de Asturias, Oviedo y Gijón- (Torío, 2011).

La evaluación de un programa consiste "en realizar un seguimiento a lo largo de un proceso que permita obtener información acerca de cómo se está llevando a cabo, con la finalidad de reajustar la intervención orientadora, de acuerdo con los datos obtenidos. Es necesario tener en cuenta en toda evaluación que ésta debe ajustarse a las características del contexto done el programa se lleva a cabo" (Hernández y Martínez, 1996, 2). Como afirma Sanz (1996, 64), la evaluación tiene que ser conceptualizada como un proceso continuo, integral en cuanto a los esfuerzos o desarrollo del programa, no como algo hilvanado al final del programa. En el caso que nos ocupa, hay necesidad de evaluar al comienzo del programa, durante el proceso y en su finalización. Consideramos como finalidad general de la evaluación del programa de educación parental la toma de decisiones para la mejora del proceso de intervención y del logro de resultados.

No hay un camino único para realizar la evaluación de un programa (Tejedor, 2000, p. 321) por lo que es necesario prestar atención a numerosos elementos a la hora de concretar un diseño o plan de análisis. Aun cuando pensamos que el diseño debe ser establecido a priori respondiendo a la concepción teórica, incluyendo referencias a los objetivos del programa, sus componentes, los recursos necesarios, las estrategias de recogida y análisis de datos, las posibles decisiones de su desarrollo y la presentación y difusión de los resultados, la postura del grupo de investigación no excluye la posibilidad de ir incorporando durante el desarrollo de la ejecución todos aquellos elementos que se consideren más favorables a la optimización del proceso planificado: reformulación de objetivos, incorporación de nuevos recursos y materiales (fichas,

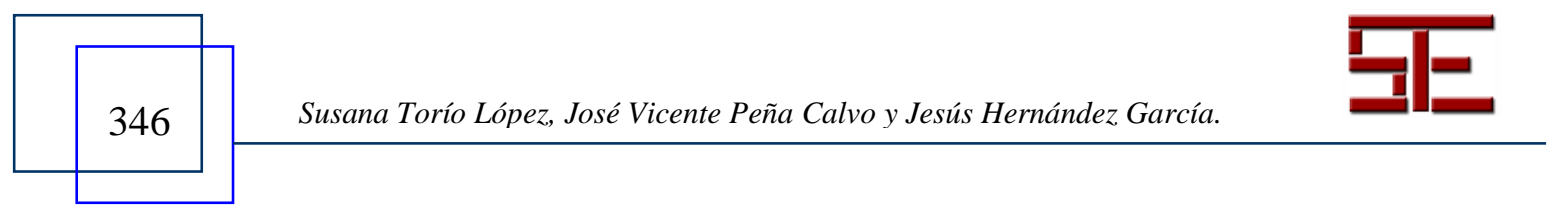




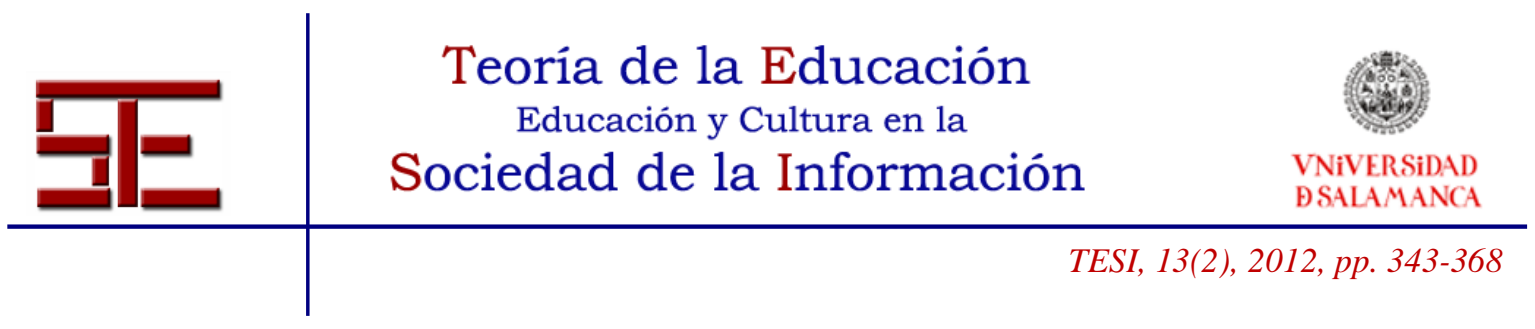

modificación o ampliación de powers point,...), modificación o ampliación de estrategias de recogida de datos, etc.

En el diseño de la evaluación del programa "Construir lo cotidiano", destacamos tres momentos: evaluación inicial, evaluación de proceso y evaluación final.

\section{1.-Evaluación inicial}

La evaluación inicial del programa, antes de su puesta en funcionamiento, es esencial por su carácter anticipador, preventivo (Pérez Juste, 1995, 87-84; 1996, 228; 2006, 218-228). El objetivo que se pretende es poner en marcha el programa en condiciones favorables, minimizando el riesgo de fracaso. Es importante destacar el trabajo que se ha realizado en la sesión inicial de contacto entre todos los participantes con objeto de crear un clima participativo. El programa trata de llevar a cabo una metodología participativa que brinda a los participantes la oportunidad de expresarse y compartir. En la sesión inicial, además de otros aspectos, se administró un cuestionario inicial mediante el cual los padres y madres pudieran proyectar las concepciones, imágenes y sentimientos que sustentan a cerca de la educación de sus hijas e hijos y de sus formas de elaborar y compartir ese modelo educativo (es decir, verbalizar el modo de ser padres y madres y aflorar sentimientos y emociones a cerca del sentimiento de la maternidad y paternidad). De igual modo, las madres y los padres cumplimentan un pretest que determina la situación de partida de los participantes en aspectos relacionados con los contenidos abordados en el programa.

\section{2.- Evaluación del proceso}

El análisis gira en torno a la marcha del programa tanto en su adecuación a la programación previa como a los aspectos dinámicos y de relación del mismo (Municio, 1991, 390; Pérez Juste, 1995, 94-101, 1996, 229-233, 2006, 230-244). La evaluación de proceso se centra, pues, en los aspectos humanos, tanto de las tareas (la forma en que se resuelven los problemas, la toma de decisiones, etc.) como de las relaciones (interrupciones en el proceso de comunicación, evitar que alguien tome el protagonismo en una situación, dejar olvidadas las buenas ideas que alguien presenta, etc.). Consideramos necesario ligar a la implantación y desarrollo del programa una evaluación procesual de carácter formativo, realizada de forma periódica en todas las fases del desarrollo del mismo y utilizada para proporcionar una rápida intercomunicación entre los miembros del equipo de investigación, de manera que se puedan hacer todo tipo de cambios con la idea de mejorar el programa. Las

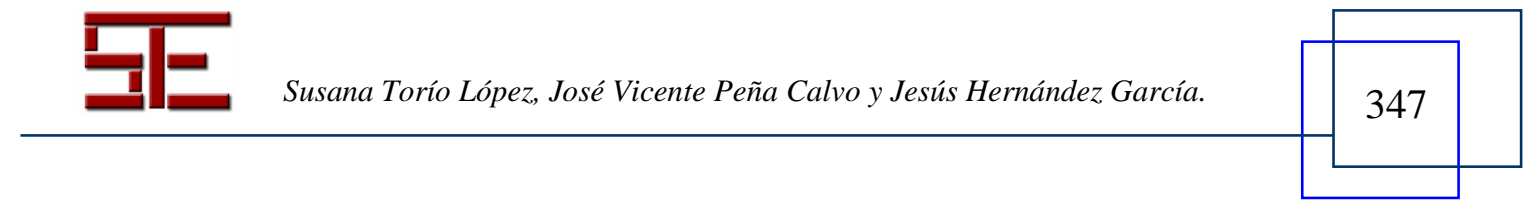




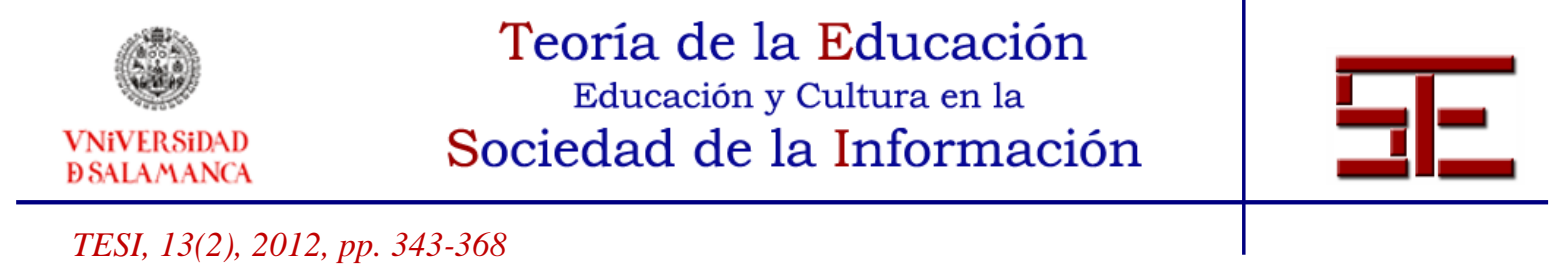

evaluaciones formativas (Sanz, 1996, 71-73) "buscan identificar distintas áreas de problemas potenciales antes de que se extiendan o intensifiquen (...), la finalidad es ayudar a mejorar el programa".

\subsection{1.- Evaluación de la implementación}

Esta fase consiste en evaluar "qué" está funcionando del programa una vez que se ha puesto en marcha, es decir, la instrumentalización del programa de intervención, su puesta en práctica siguiendo las etapas previamente concretadas. El fin último de esta fase es contrastar si hay o no discrepancias entre el diseño y la realidad; y en caso afirmativo, realizar la adaptación pertinente, redefinir el programa para lograr su óptima y adecuada puesta en marcha (Hernández y Martínez, 1996, 8; Pérez Juste, 2000, 277; Tejedor, 2000, 327). En síntesis, facilitar la toma a tiempo de decisiones de mejora y acumular información para introducir mejoras en futuras aplicaciones. En este sentido, el marco (contexto, clima, ambiente) es un elemento fundamental que puede interferir en el desarrollo del programa.

En cuanto a la metodología general a utilizar en la recogida de información en esta fase, destacamos: el diario del educador o educadora, la hoja de notas que se facilita al término de cada sesión a fin de recoger aspectos significativos e impresiones que han ocurrido en el desarrollo de la sesión, los cuestionarios de evaluación de cada sesión cumplimentada por los padres y madres, el cuestionario del educador o educadora de cada sesión, así como las actividades realizadas en cada sesión y el diálogo y comunicación que vayan surgiendo en el desarrollo de la misma. Es importante dar un gran valor al seguimiento del programa en el día a día; en concreto, la observación del comportamiento del grupo de padres y madres por parte del educador o educadora. Asimismo, dentro de esta fase se tratará de determinar si los participantes en el programa van modificando sus pautas de comportamiento en las áreas que se trabajan a lo largo de su desarrollo.

En lo que atañe al análisis de los datos, se realiza en base tanto a un análisis cuantitativo como cualitativo. En ambos casos se dirige la búsqueda de las causas, dificultades que existan en el desarrollo del programa, bien sea por deficiencias en su diseño o por las características del contexto. Los instrumentos de recogida de información han sido elaborados para tal fin.

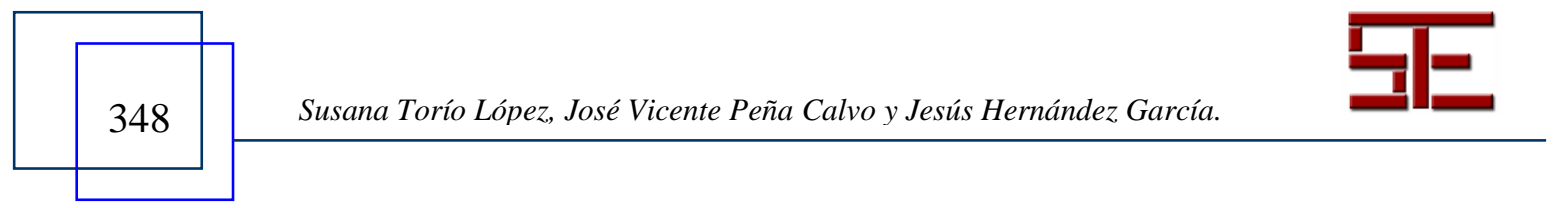




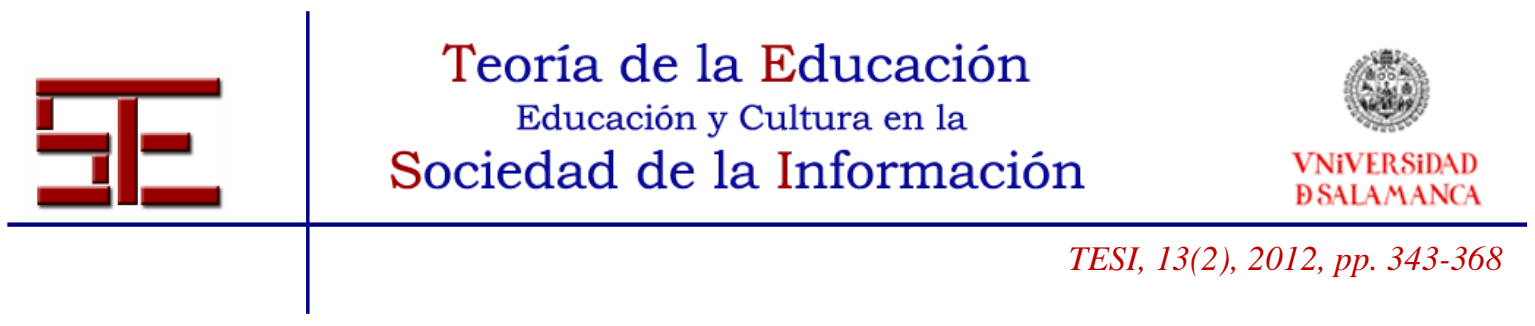

Respecto de la temporalización, la recogida de información se ha realizado de modo continuado a lo largo del programa. Así, se lleva un control diario del desarrollo de las sesiones por parte de los educadores o educadoras en el que se tomarán notas de las actividades, incidencias, materiales y recursos utilizados. Se ha prefijado en el programa en qué momento han de ser utilizados los instrumentos específicos. Hemos de decir que, para la aplicación, a cada centro educativo han acudido dos miembros del grupo de investigación, conocedores del programa debido a que han participado en su diseño.

En síntesis, se trata de poder realizar correctamente la comparación entre lo planificado y lo realizado. Lo que interesa en esta fase es evaluar la identificación y adecuada selección de las actividades que constituyen y definen el programa separando lo que es esencial y definitorio de lo accesorio (Alvira, 1991, 39).

\subsection{2.- Evaluación de desarrollo}

Si la evaluación de implementación explica el "qué" se hace en un programa, la evaluación de desarrollo explica el "cómo", es decir, qué requisitos debe cumplir el proceso de puesta en marcha para que se considere adecuado, correcto, acorde con un buen desarrollo del mismo (Hernández y Martínez, 1996, 11). En cuanto a la metodología, se utilizan los instrumentos señalados para la evaluación de la implementación del programa y, de igual modo, lo señalado en la temporalización de la evaluación.

\section{3.- Evaluación final}

1.4 .

Se trata de comprobar en qué medida se están alcanzando los resultados previstos y también los resultados no previstos y los efectos (Pérez Juste, 1995, 101105, 1996, 234-235, 2000, 277; Boutin y Durning, 1997, 210-214; Tejedor, 2000, 326326). Recoger información para saber si el programa está o no consiguiendo los resultados esperados: ¿se están consiguiendo los resultados esperados?, ¿los resultados obtenidos son efecto del programa desarrollado o de otros aspectos no contemplados?

Es una evaluación sumativa en el sentido de que permite la visión de conjunto del proyecto y la obtención de aprendizajes, valoraciones y posibilidades de mejora muy superiores al resto de evaluaciones (Municio, 1992, 391).

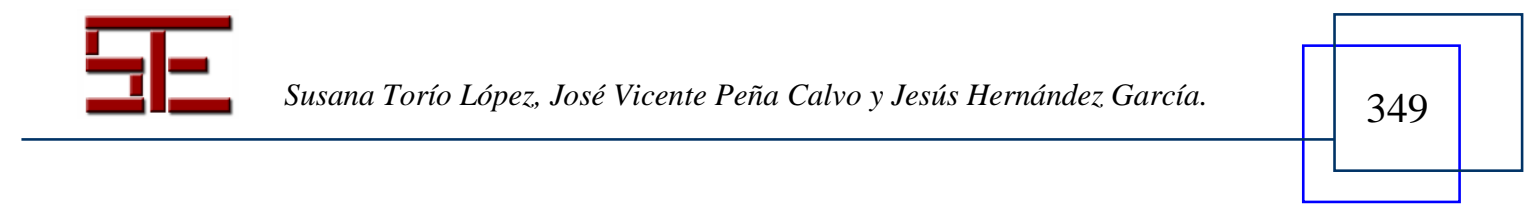




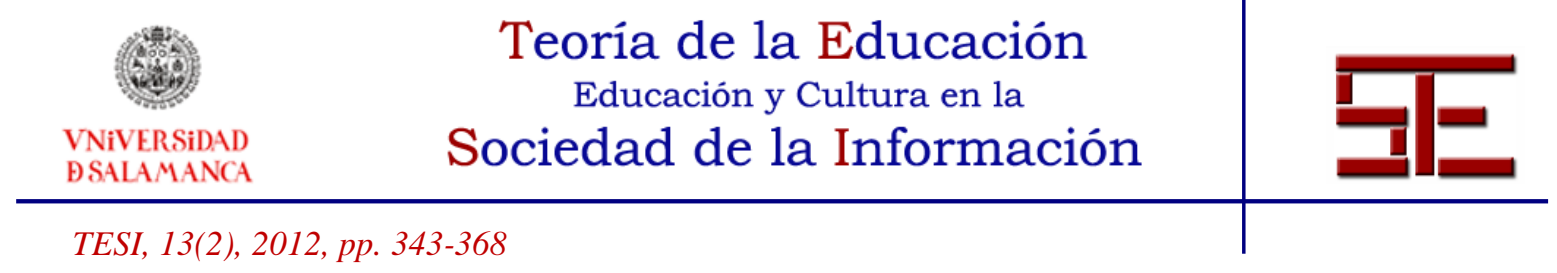

Respecto a la metodología, cabe reiterar lo establecido en fases anteriores, si bien hemos hecho más hincapié en los instrumentos a fin de facilitar la recogida tanto de datos cuantitativos, como cualitativos.

Se ha desarrollado una sesión 10 con objeto de realizar una evaluación de los resultados, del logro de los objetivos, así como del impacto y efectos del programa. Se ofrece un cuestionario de evaluación final dirigido a madres y padres que han participado. Mediante el mismo, el educador o educadora que ha implementado el programa trata de averiguar si se han producido cambios a corto plazo en las cogniciones y comportamientos en los participantes. También pretende conocer el grado de satisfacción y utilidad del programa, así como detectar posibles propuestas de mejora. De igual modo, en una dinámica que se realiza en dicha sesión, a través de un documento de trabajo, se obtienen interesantes valoraciones de las familias sobre los efectos y logros alcanzados con el programa y los cambios a corto plazo en su comportamiento en las áreas trabajadas.

De igual modo, es importante acceder a una evaluación institucional, es decir, las observaciones que, de forma espontánea o directamente, los implicados en el programa hayan hecho llegar a los responsables de la Escuela de Madres y Padres o en el centro educativo en que se haya desarrollado. Obtendremos dicha información a través de algunas entrevistas a personal responsable del centro al finalizar la implementación del programa: orientadores u orientadoras de los centros educativos, presidenta de la AMPA, director o directora del centro, etc.; todas ellas personas de referencia en la captación de familias y punto de contacto a lo largo de la aplicación programática.

Finalmente, se realizará una evaluación de seguimiento con el mismo instrumento que se ha aplicado en la fase inicial del programa. La temporalización de esta etapa se realizará a los tres, y en función de los resultados se estudiará volverlo a aplicar después de transcurrido más tiempo. Se llevará a cabo dicho seguimiento por correo postal, vía e-mail, persona de contacto, etc., a considerar en cada centro.

Centramos la atención, en estas páginas, en la evaluación procesual formativa y en la final, con objeto de presentar los primeros resultados de la evaluación del programa tomando como referencia algunos de los instrumentos elaborados para tal fin: cuestionario de evaluación de madres y padres al final de cada sesión (sesión 1 a 9) y cuestionario final del programa para madres y padres (sesión 10).

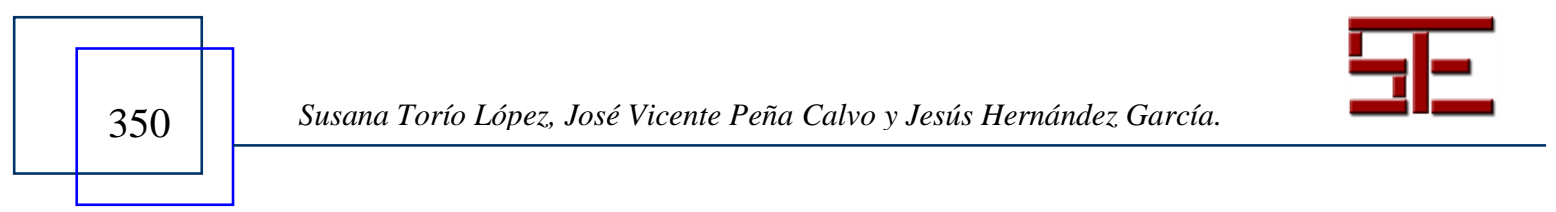




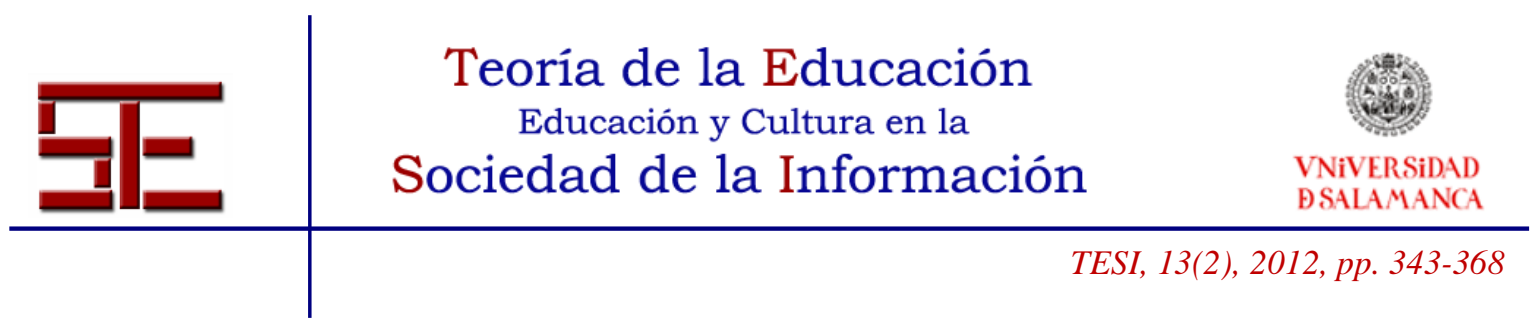

\section{2.- METODOLOGÍA}

\section{1.- Muestra}

Los participantes en la aplicación y desarrollo del programa han sido 34 personas, 16 varones $(47.1 \%)$ y 18 mujeres $(52.9 \%)$. La presencia de dos mujeres más, respecto a los hombres, es debido a que son dos familias monoparentales. La media de edad es 42.88 en los varones y 42.28 en las mujeres. La edad media en la que se han convertido en padres ha sido a los 35 años. Por centros, se han encontrado diferencias estadísticamente significativas $\left(\chi^{2}=10.78 ; \mathrm{p}=0.01\right)$, con una media de 31 años de edad han sido padres en uno de los centros, seguidos por 32.6, 35.17 y 37.50 . La media de hijos o hijas en los cuatro centros es de uno por familia, con la excepción en uno de los centros, donde ha participado una familia con tres descendientes: dos hijos y una hija. Respecto al sexo del primer descendiente, en tres de los centros el valor más encontrado ha sido el de los varones, y en uno, las niñas. En relación con el segundo hijo, se repite lo mismo, en tres centros el segundo descendiente con mayor frecuencia es un varón. Por lo que respecta a la edad del primer hijo, no se han encontrado diferencias estadísticamente significativas, mientras que en la edad del segundo descendiente sí existen diferencias estadísticamente significativas como la muestra la prueba de Kurskal-Wallis $\left(\chi^{2}=7 ; \mathrm{p}<0.05\right)$. Referente al nivel de estudios, se han encontrado diferencias estadísticamente significativas $\left(\chi^{2}=16.82 ; \mathrm{p}<0.01\right)$ : el $35,3 \%$ de los participantes han alcanzado los estudios universitarios medios, el 25,5 universitarios superiores, el $20.6 \%$ formación profesional, el $8.8 \%$ educación secundaria, el $5.9 \%$ estudios primarios y un $2.9 \%$ han alcanzado el nivel de doctor.

\section{2.-Instrumentos de evaluación y procedimiento}

En estas líneas vamos a hacer referencia, especialmente, a dos cuestionarios implementados durante la aplicación del programa en los centros educativos, dejando otros instrumentos que serán considerados para la ampliación del estudio (diario del educador o educadora, hojas de notas de cada sesión, cuestionario de fin de sesión del educador o educadora, entre otros). Describamos brevemente ambos instrumentos.

- El cuestionario de evaluación de madres y padres al final de cada sesión (sesión 1 a la 9) consta de once preguntas, de las cuales nueve son de respuesta cerrada; seis preguntas son con respuestas de no (1) y sí (2); y tres son de cuatro alternativas de respuesta: nunca (1), a veces (2), casi siempre (3) y siempre (4). Las temáticas

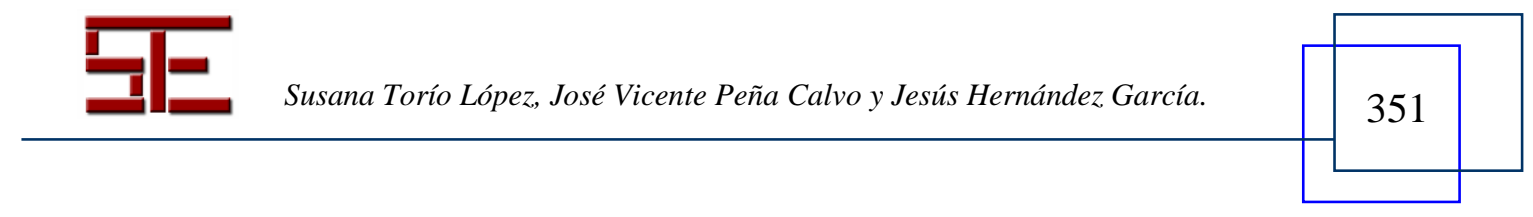




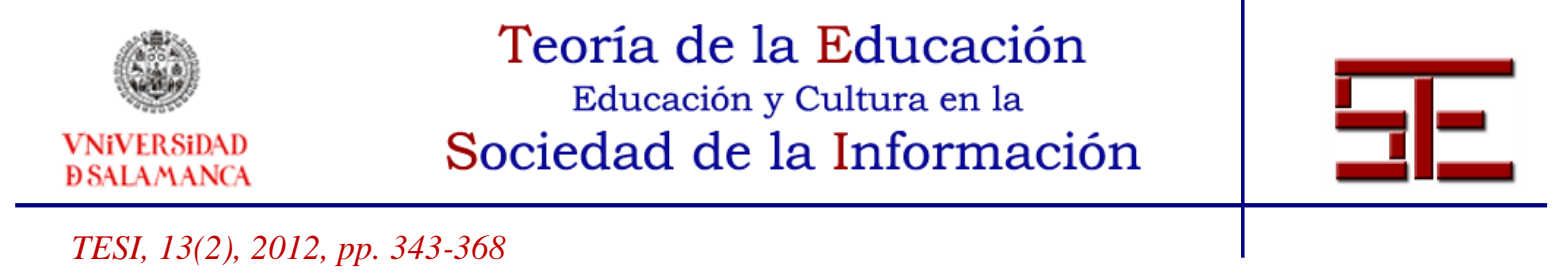

abordadas están en relación con: la claridad en los objetivos, la forma de explicar por parte del educador o educadora, la resolución de dudas, el interés de los contenidos, la adecuación de las dinámicas de cada sesión, el clima de trabajo logrado, la facilidad de expresar inquietudes, la participación de buen grado y el compromiso con las actividades para casa. Finaliza con dos preguntas abiertas para valorar lo mejor de la sesión y lo que ha echado en falta en el trascurso de la misma.

- El cuestionario de evaluación final del programa para padres y madres (sesión 10) consta de ocho preguntas de respuesta cerrada, cinco con respuestas de no (1) y sí (2) y tres de cuatro alternativas de respuesta: nunca (1), a veces (2), casi siempre (3) y siempre (4). Además, cuenta con once preguntas abiertas en las que se requiere justificar y ampliar la información de las respuestas cerradas.

Ambos instrumentos han sido aplicados al finalizar la sesión de trabajo. Para la intervención en cada centro, se elaboró un calendario de aplicación del programa acomodándose el equipo de investigación a los intereses de las familias (día de la semana, hora, períodos vacacionales y fiestas, etc.).

\section{3.- RESULTADOS}

\section{1. -Análisis de la evaluación formativa durante el transcurso del programa}

Para poder determinar el nivel de satisfacción de los participantes con el transcurso del programa, se procede a analizar los resultados obtenidos en los cuestionarios que eran cumplimentados por los participantes al finalizar cada sesión. Se presentan los resultados de nueve sesiones, ya que los resultados de la sesión 10 se exponen en el apartado siguiente.

Este instrumento consta de preguntas abiertas y cerradas. Las puntuaciones de las preguntas cerradas son consideradas como dimensiones, por lo que se ha optado por obtener las medias y las desviaciones típicas ${ }^{2}$. El número total de cuestionarios es de 229, distribuidos a lo largo de las nueve sesiones. Al equipo investigador le interesa evaluar cómo ha sido la evaluación del programa, por parte de sus participantes, durante

\footnotetext{
${ }^{2}$ Las desviaciones típicas han sido calculadas (la mayoría de las variables tienen un valor de cero en este descriptivo), no se han insertado en las tablas por problemas de espacio
}

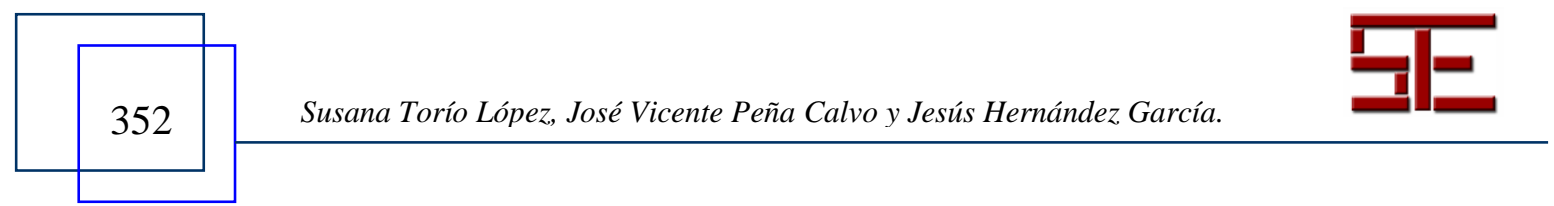




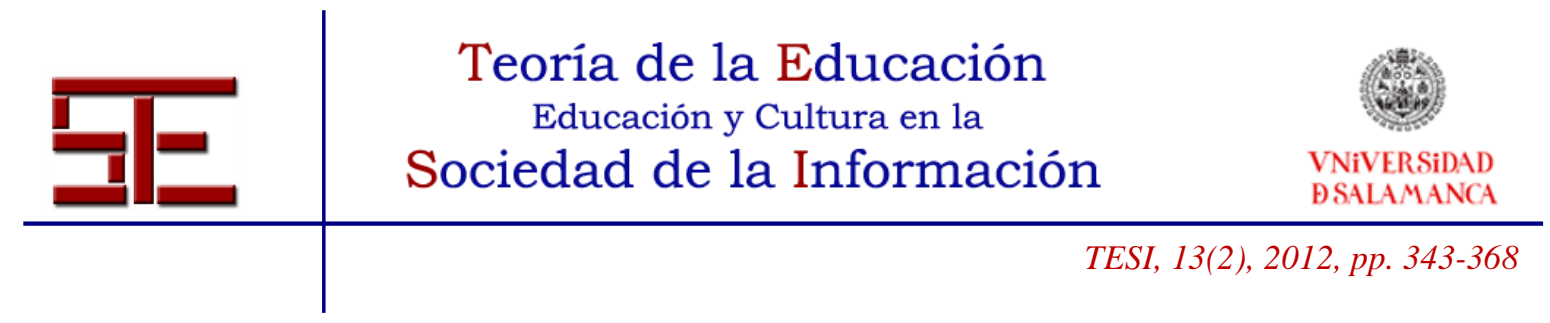

su transcurso. Para ello se va a proceder a realizar una comparación de medias entres sesiones en los cuatro centros educativos del estudio piloto.

La muestra no tiene una distribución de normalidad, como indican los índices de asimetría y curtosis, y tampoco existe homogeneidad en las varianzas. Ante esta situación, se emplea la prueba no paramétrica de Kruskal-Wallis para ver si existen diferencias estadísticamente significativas entre las nueve sesiones, en los aspectos evaluados por el cuestionario.

Este análisis ha mostrado que no existen diferencias estadísticamente significativas en cada uno de los aspectos evaluados, a lo largo de las nueve sesiones, en ninguno de los cuatro centros (Ver Tabla 1, Tabla 2, Tabla 3 y Tabla 4).

Tabla 1. Promedios en las respuestas obtenidas en los cuestionarios de evaluación final en las nueve sesiones $(n=58)$. Centro 1

\begin{tabular}{lccccccccc}
\hline \multicolumn{7}{c}{ Sesiones } \\
\hline Aspectos a evaluar & $S \_1$ & $S \_2$ & $S \_3$ & $S \_4$ & $S \_5$ & $S \_6$ & $S \_7$ & $S \_8$ & $S \_9$ \\
\hline Objetivos sesión & 2 & 2 & 2 & 2 & 2 & 2 & 2 & 2 & 2 \\
\hline Explicación clara & 2 & 2 & 2 & 2 & 2 & 2 & 2 & 2 & 2 \\
\hline Respuestas a las dudas & 3.6 & 3.9 & 3.83 & 3.8 & 3.86 & 3.83 & 4 & 3.67 & 3.67 \\
\hline Contenidos interesantes & 2 & 2 & 1.67 & 2 & 2 & 2 & 2 & 2 & 2 \\
\hline Actividades adecuadas & 2 & 2 & 2 & 2 & 2 & 2 & 2 & 2 & 2 \\
\hline Buen clima de trabajo & 3.2 & 4 & 3.67 & 3.8 & 3.71 & 3 & 4 & 3.67 & 3.83 \\
\hline Facilidad expresión & 3.2 & 3.5 & 3.67 & 3.8 & 3.57 & 3 & 4 & 3.67 & 3.67 \\
\hline Participación & 2 & 2 & 2 & 2 & 2 & 2 & 2 & 2 & 2 \\
\hline
\end{tabular}

Tabla 2. Promedios en las respuestas obtenidas en los cuestionarios de evaluación final en las nuevas sesiones $(\mathbf{n}=40)$. Centro 2

\begin{tabular}{llllllllll}
\hline \multicolumn{1}{c}{ Sesiones } \\
\hline Aspectos a evaluar & $S \_1$ & $S \_2$ & $S \_3$ & $S \_4$ & $S \_5$ & $S \_6$ & $S \_7$ & $S \_8$ & $S \_9$ \\
\hline Objetivos sesión & 2 & 1.8 & 2 & 2 & 2 & 2 & 2 & 2 & 2 \\
\hline Explicación clara & 2 & 2 & 2 & 2 & 2 & 2 & 2 & 2 & 2 \\
\hline Respuestas a las dudas & 3.6 & 3.6 & 4 & 4 & 4 & 4 & 4 & 3.8 & 3.6 \\
\hline Contenidos interesantes & 2 & 2 & 2 & 2 & 2 & 2 & 2 & 2 & 2 \\
\hline Actividades adecuadas & 2 & 2 & 2 & 2 & 2 & 2 & 2 & 2 & 2 \\
\hline Buen clima de trabajo & 3.8 & 4 & 4 & 3.67 & 4 & 4 & 3 & 3.6 & 4 \\
\hline Facilidad expresión & 3.8 & 4 & 4 & 3.67 & 3.67 & 3.75 & 3 & 3.8 & 4 \\
\hline Participación & 2 & 2 & 2 & 2 & 2 & 2 & 2 & 2 & 2 \\
\hline
\end{tabular}

Susana Torío López, José Vicente Peña Calvo y Jesús Hernández García. 


\begin{tabular}{c} 
Teoria de la Educación \\
Educación y Cultura en la \\
$\begin{array}{c}\text { VNiVERSIDAD } \\
\text { BSALAMANCA }\end{array}$ \\
\hline TESI, 13(2), 2012, pp. $343-368$
\end{tabular}

Tabla 3. Promedios en las respuestas obtenidas en los cuestionarios de evaluación final en las nuevas sesiones $(n=62)$. Centro 3

\begin{tabular}{llllllllcc}
\hline \multicolumn{1}{c}{ Sesiones } \\
\hline Aspectos a evaluar & $S_{-} 1$ & $S_{-} 2$ & $S_{-} 3$ & $S_{-} 4$ & $S \_5$ & $S \_6$ & $S \_7$ & $S \_8$ & $S \_9$ \\
\hline Objetivos sesión & 2 & 2 & 2 & 1.78 & 2 & 2 & 2 & 2 \\
\hline Explicación clara & 2 & 2 & 2 & 2 & 2 & 2 & 2 & 2 \\
\hline Respuestas a las dudas & 3.67 & 3.87 & 3.86 & 3.78 & 3.86 & 3.86 & 3.80 & 3.50 \\
\hline Contenidos interesantes & 2 & 2 & 2 & 2 & 2 & 2 & 2 & 2 \\
\hline Actividades adecuadas & 2 & 2 & 2 & 2 & 2 & 2 & 2 & 1.90 \\
\hline Buen clima de trabajo & 3.78 & 3.87 & 4 & 4 & 3.86 & 4 & 4 & 3.90 \\
\hline Facilidad expresión & 3.78 & 4 & 4 & 4 & 4 & 3.57 & 4 & 3.70 \\
\hline Participación & 2 & 2 & 2 & 2 & 2 & 2 & 2 & 2 \\
\hline
\end{tabular}

Tabla 4. Promedios en las respuestas obtenidas en los cuestionarios de evaluación final en las nuevas sesiones $(\mathrm{n}=69)$. Centro 4

\begin{tabular}{llllllllll}
\hline \multicolumn{1}{c}{ Sesiones } \\
\hline Aspectos a evaluar & $S \_1$ & $S_{-} 2$ & $S_{-} 3$ & $S_{-} 4$ & $S_{-5}$ & $S_{-} 6$ & $S_{-} 7$ & $S_{-} 8$ & $S \_9$ \\
\hline Objetivos sesión & 2 & 2 & 2 & 2 & 2 & 2 & 2 & 2 & 2 \\
\hline Explicación clara & 2 & 2 & 2 & 2 & 2 & 2 & 2 & 2 & 2 \\
\hline Respuestas a las dudas & 3.45 & 3.50 & 3.89 & 3.60 & 4 & 3.87 & 3.86 & 3.86 & 3.78 \\
\hline Contenidos interesantes & 2 & 2 & 2 & 2 & 1.60 & 2 & 2 & 2 & 1.78 \\
\hline Actividades adecuadas & 1.73 & 2 & 2 & 2 & 2 & 2 & 2 & 2 & 2 \\
\hline Buen clima de trabajo & 3.64 & 4 & 3.44 & 4 & 4 & 3.88 & 3.86 & 3.71 & 4 \\
\hline Facilidad expresión & 3.1 & 3 & 3.11 & 3 & 3.60 & 3.63 & 3.29 & 3.86 & 3.44 \\
\hline Participación & 2 & 2 & 1.89 & 2 & 2 & 2 & 2 & 2 & 2 \\
\hline
\end{tabular}

Siguiendo el esquema del cuestionario empleado, podemos destacar los siguientes resultados:

- En los cuatro centros, se observa que los participantes dicen que el educador o educadora ha dejado claro el objetivo de cada una de las sesiones. En el centro 2, en la sesión 2 (Imágenes de maternidad y paternidad), y en el centro 3, en la sesión 5 (La participación de los hijos en las tareas domésticas), se ha observado una ligera disminución en las respuestas afirmativas.

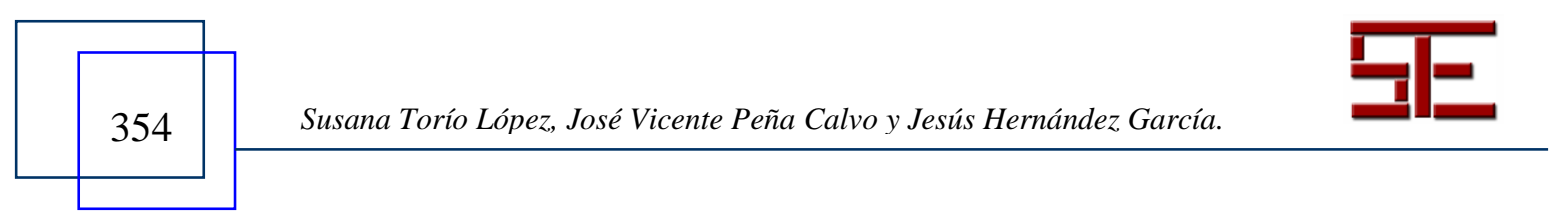




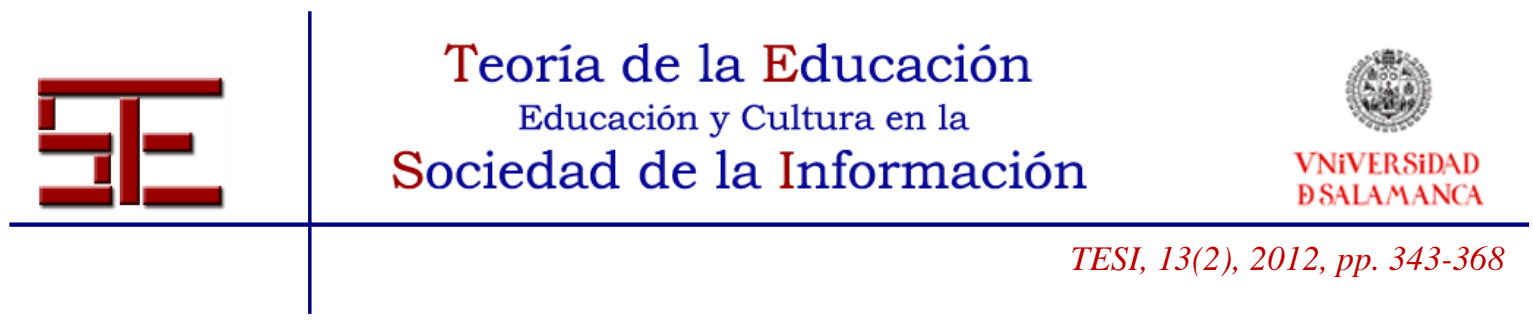

- Respecto al nivel de claridad y precisión del educador o educadora a lo largo de cada una de las sesiones, como se puede ver en las Tablas 1, 2, 3 y 4, todos los participantes han emitido respuestas afirmativas en este sentido.

- Los participantes han contestado entre "casi siempre" y "siempre" que las educadoras o los educadores han respondido a las dudas de manera adecuada.

- Respecto de los contenidos de cada una de las sesiones, la mayoría de los participantes han contestado afirmativamente a esta pregunta. En el centro 1, la media de respuesta se encuentra por debajo del dos en la sesión tercera (Modos de educar en familia), y en el centro 4, la sesión quinta (La participación de los hijos e hijas en las tareas domésticas). - Los participantes han contestado afirmativamente un $80 \%$ a la pregunta sobre la pertinencia de las actividades realizadas en cada una de las sesiones. En el centro 3, la media a esta pregunta está ligeramente por debajo de 2; y en el centro 4, ocurre algo parecido con la sesión primera (Una mirada a nuestro quehacer educativo).

- El clima de trabajo ha sido considerado el adecuado entre "casi siempre" y "siempre", en los cuatro centros educativos, a lo largo de las nueve sesiones. Similar resultado ha habido en la pregunta sobre la facilidad que han tenido los participantes en expresar sus inquietudes y problemas ante el grupo.

- Por último, cuando se les ha preguntado si han participado de buen grado en las actividades propuestas en cada sesión, todos los centros han contestado afirmativamente en todas las sesiones, excepción hecha en el centro 4, en la sesión tercera (Modos de educar en familia).

En el cuestionario de fin de sesión se incorporan dos preguntas abiertas respecto a lo que consideran que ha sido lo mejor de la sesión y, por otro lado, qué han echado en falta en la misma. Veamos algunas de sus aportaciones, a modo de ejemplo, en la Tabla 5 .

Tabla 5. Valoración general de cada sesión (Cuestionario de fin de sesión para madres y padres)

\begin{tabular}{|c|c|c|c|}
\hline & Lo mejor de esta sesión ha sido ... & He echado en falta.... \\
\hline 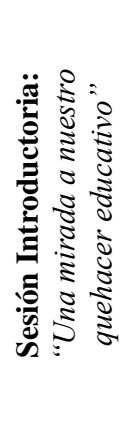 & $\begin{array}{l}\stackrel{\circ}{\sigma} \\
\frac{0}{\infty} \\
\stackrel{\infty}{\infty}\end{array}$ & $\begin{array}{l}\text { " "Rendir cuenta a mí misma de por qué estoy aquí". } \\
\text { " "Autoanalizarnos a nosotros mismos y ver un poco nuestros puntos } \\
\text { débiles". } \\
\text {. "Visualizar nuestro papel de padres y madres y la forma de } \\
\text { relacionarnos con nuestros hijos". } \\
\text {."Se aprende oyendo hablar a los demás, especialmente, a quien } \\
\text { tiene más experiencia". } \\
\text {."Reafirmarme en las cosas buenas, ver que los problemas son } \\
\text { comunes". } \\
\text { "El ser pocos y con las preguntas ir conociéndonos y atrevernos a } \\
\text { expresarnos sin vergüenza". } \\
\text { "Motivarnos a participar". }\end{array}$ & $\begin{array}{l}\text {. "Un poco más de tiempo para } \\
\text { profundizar sobre los temas" } \\
\text { " "Romper un poco más a expresarme" }\end{array}$ \\
\hline
\end{tabular}

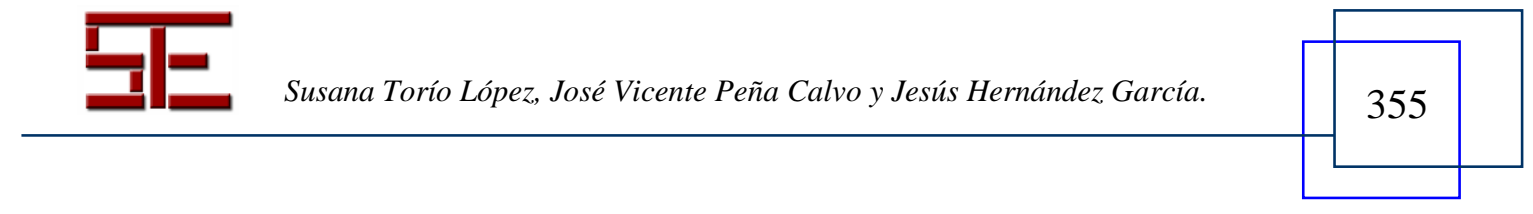




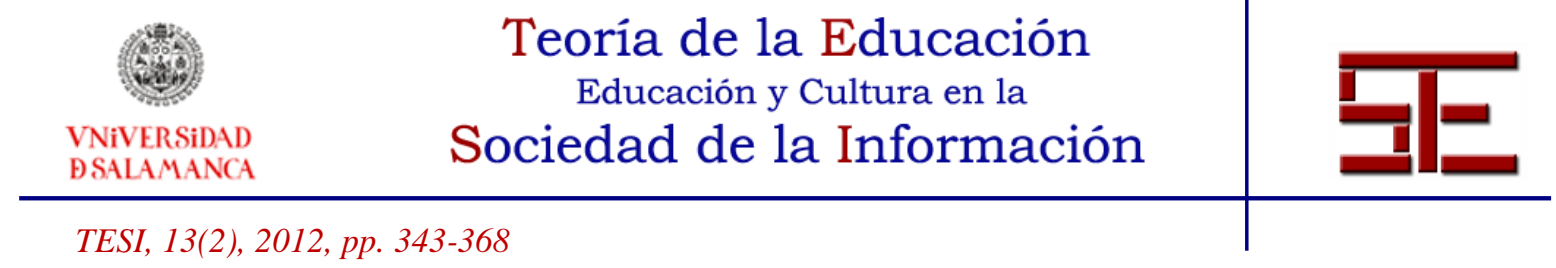

\begin{tabular}{|c|c|c|c|}
\hline & 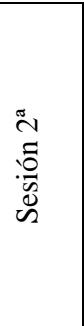 & $\begin{array}{l}\text { "El análisis de los valores realmente importantes para nuestra vida } \\
\text { en familia y en pareja. Te hace pensar lo verdaderamente } \\
\text { importante" } \\
\text {."Generación de un clima de confianza en el grupo" } \\
\text {."El trabajo en grupo", "el poner en común las parejas nuestras } \\
\text { respuestas", "puesta en común y discusión". }\end{array}$ & $\begin{array}{l}\text { "Más tiempo y más intercambio de } \\
\text { ideas" } \\
\text { " "Participación, se me ha hecho muy } \\
\text { corto" } \\
\text {. "Más tiempo para hablar de la } \\
\text { compatibilidad familia- pareja- trabajo". } \\
\text { "Únicamente que más de dos horas en la } \\
\text { ludoteca a los niños seguro que se les ha } \\
\text { hecho largo". }\end{array}$ \\
\hline 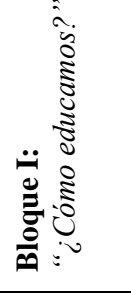 & 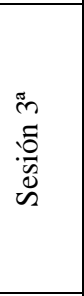 & $\begin{array}{l}\text { "La manera de poner las normas", "Identificar las normas", "El } \\
\text { contenido relativo a las normas"... } \\
\text { "Hemos pasado a concretar más, ejemplo más cotidianos". } \\
\text { "Saber que tenía un modelo educativo democrático". } \\
\text {."Descubrir cómo afecta la edad de los niños a su capacidad de ser } \\
\text { responsables". } \\
\text { "El debate", "la reflexión", "participación". } \\
\text { "Lo que vamos aprendiendo". }\end{array}$ & $\begin{array}{l}\text { Surgen muchas cosas que no nos da } \\
\text { tiempo a exponer" } \\
\text { "Más tiempo" } \\
\text { "Más casos prácticos" } \\
\text { "Más exposiciones de los padres" }\end{array}$ \\
\hline 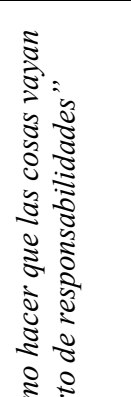 & 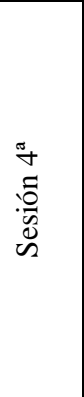 & $\begin{array}{l}\text {. "Los distintos puntos de vista de los otros asistentes y la puesta en } \\
\text { común". } \\
\text { "El cuestionario (dinámica de sesión) pues me interesaba este tipo } \\
\text { de herramienta para comparar resultados con mi pareja". } \\
\text { "Ver el resultado de la dinámica, me puntuó diferente de lo que } \\
\text { pensaba". } \\
\text { "Enumerar la tareas no solo domésticas, sino todo lo relacionado } \\
\text { con la vida cotidiana". } \\
\text { "Reconocimiento de los roles y tareas que ocupa cada miembro y } \\
\text { las dinámicas". } \\
\text { "El punto de vista de cada componente de la pareja". }\end{array}$ & "Nada". \\
\hline 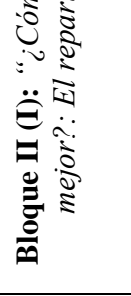 & in & $\begin{array}{l}\text { "Pensar en estrategias para modificar problemas del reparto de } \\
\text { tareas". } \\
\text {."Cómo favorecer la participación del niño". } \\
\text {."propuestas para favorecer la participación de los hijos puesto que } \\
\text { representan un abanico de posibilidades muy interesante". } \\
\text { "Clima creado, dinámica de grupo". } \\
\text { "Como grupo, la comunicación".. } \\
\text {."Oír a los demás con los mismos problemas" }\end{array}$ & $\begin{array}{l}\text { "Nada" } \\
\text { "Más tiempo, como siempre..." }\end{array}$ \\
\hline 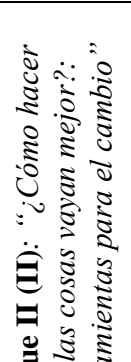 & 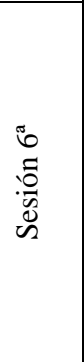 & $\begin{array}{l}\text { "La tranquilidad de hablar con los demás de los temas". } \\
\text { "Los conflictos de pareja, pero ¿es que es tan complicada la } \\
\text { convivencia?". } \\
\text { "Distintos puntos de vista: masculino y femenino". } \\
\text { "Ver que los contenidos se reflejan en el día a día". } \\
\text { "Cosas que pensaba que solo pasaban en mi casa y resulta que son } \\
\text { casos típicos". } \\
\text {."Expresar conflictos y situaciones que nos pasan en el día a día". } \\
\text { "Tratar de mejorar las actuaciones en casa con la familia } \\
\text { dialogando". }\end{array}$ & $\begin{array}{l}\text { "Más casos concretos" } \\
\text { "Un poco más de tiempo" } \\
\text { "Trabajar más el diálogo en grupo". }\end{array}$ \\
\hline 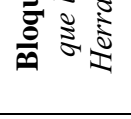 & 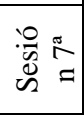 & $\begin{array}{l}\text { "El buen clima", "comunicación", "divertido con los } \\
\text { compañeros"... } \\
\text { "La dinámica de hoy ha sido divertida y muy interesante". }\end{array}$ & $\begin{array}{l}\text { "Más ejemplos (más tiempo)". } \\
\text { "Puesta en común y debate". } \\
\text { "Creo que ha sido una de las mejores }\end{array}$ \\
\hline
\end{tabular}

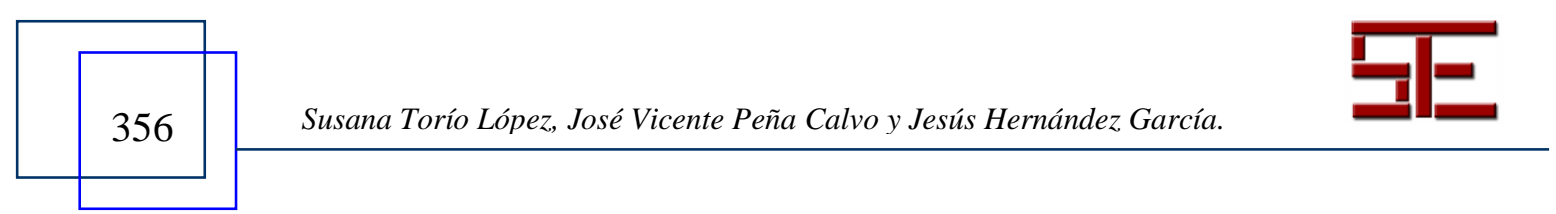




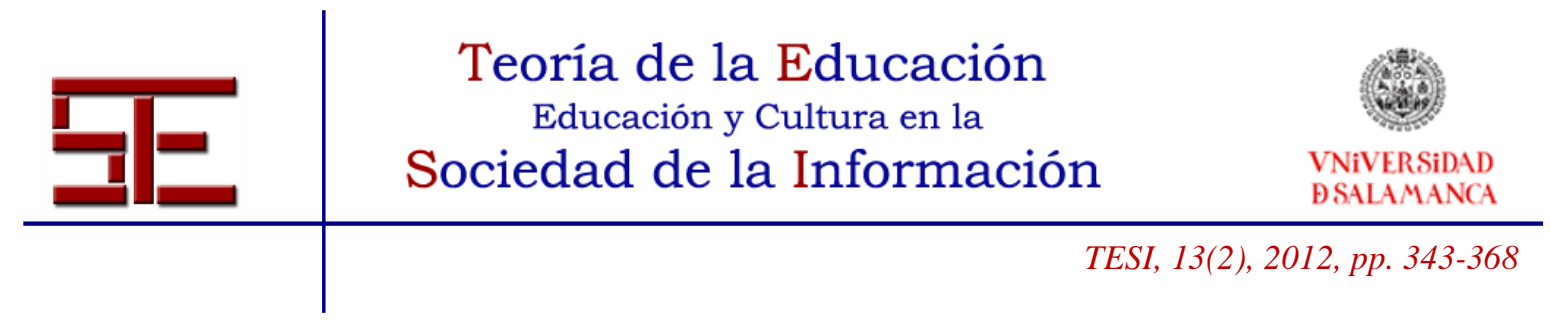

\begin{tabular}{|c|c|c|c|}
\hline & & $\begin{array}{l}\text { "Nos da herramientas para mejorar la comunicación en nuestra } \\
\text { familia". }\end{array}$ & sesiones". \\
\hline & 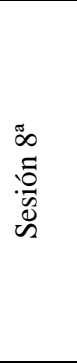 & $\begin{array}{l}\text { "“'Identificar las posibles aplicaciones de lo aprendido en uno } \\
\text { mismo". } \\
\text { " "Trabajo en grupo y lo bien que lo pasamos". } \\
\text {." Escuchar los comentarios de los otros participantes". } \\
\text { " "Intentar solucionar los problemas teniendo en cuenta los } \\
\text { sentimientos del otro e intentar también solucionarlo o decírselo sin } \\
\text { que le moleste". } \\
\text { "Importancia del lenguaje verbal y gestual. } \\
\text { "He descubierto que me comunico bastante mal con mi familia". } \\
\text { " Espero que estas charlas me ayuden a comunicarme mejor". }\end{array}$ & $\begin{array}{l}\text {." Más casos prácticos y más dinámicas } \\
\text { de grupo". } \\
\text {."Me interesa mucho la comunicación". } \\
\text {."Más tiempo". }\end{array}$ \\
\hline & 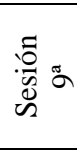 & $\begin{array}{l}\text { "Puesta en común de casos prácticos". } \\
\text { " "Clima de confianza". } \\
\text { " Explicaciones particulares sobre los vídeos". } \\
\text {."Aprender a solucionar conflictos es bastante difícil" }\end{array}$ & $\begin{array}{l}\text { " "Más tiempo" } \\
\text {."Más práctica" }\end{array}$ \\
\hline 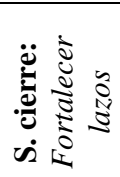 & 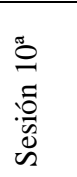 & . Cuestionario de evaluación final del programa para madres y padres. & \\
\hline
\end{tabular}

En síntesis, las madres y los padres se sienten reforzados con el intercambio de experiencias y debate de los otros participantes, además de crearse un ambiente positivo, relajado, agradable e, incluso, divertido, que ha facilitado la posibilidad de intervenir de forma sincera y lograr la participación de todos. Se demanda en todas las sesiones más tiempo. Perciben que algunas inquietudes son compartidas por otros padres y madres, y proyectan sentimientos e imágenes acerca de la educación de sus hijos e hijas.

\section{2. - Análisis de la evaluación formativa en la última sesión}

Al equipo investigador le interesa tener un indicador del carácter formativo que ha tenido el programa para los participantes. Para ello se han realizado los análisis correspondientes con las respuestas que éstos han dado en el cuestionario final (sesión de cierre).

Las puntuaciones de las preguntas cerradas del cuestionario son consideradas, igualmente, como dimensiones, por lo que se ha optado por obtener las medias y las desviaciones típicas. 


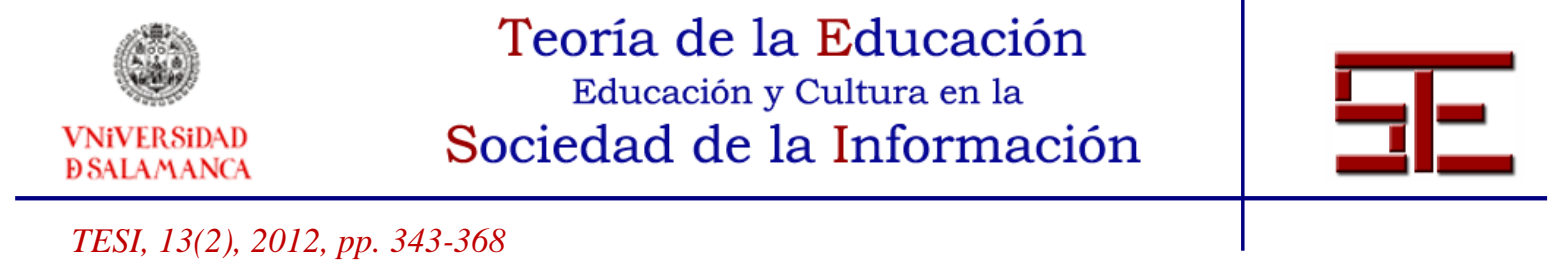

La muestra, 27 participantes que cumplimentaron este instrumento, no seguía una distribución de normalidad y tampoco se cumplía el principio de homocedasticidad (Levene $\leq 0.05$ ), por lo que se ha optado por emplear la prueba no paramétrica de Kruskal-Wallis para ver si existen diferencias estadísticamente significativas entre los centros participantes.

En las respuestas de los cuatro centros se han encontrado niveles de satisfacción muy elevados (ver Tabla 6).

Tabla 6. Promedios y desviaciones típicas en las respuestas obtenidas en el cuestionario de evaluación final del programa para madres y padres $(n=27)$

\begin{tabular}{lcccccccc}
\hline & \multicolumn{2}{c}{ Colegio 1} & \multicolumn{2}{c}{ Colegio 2} & \multicolumn{2}{c}{ Colegio 3 } & \multicolumn{2}{c}{ Colegio 4 } \\
\hline Aspectos a evaluar & Media & D.T. & Media & D.T. & Media & D.T. & Media & D.T. \\
\hline Secuenciación de las sesiones & 2 & .00 & 2 & .00 & 2 & .00 & 2 & .00 \\
\hline Contenidos & 3.14 & .69 & 3.60 & .24 & 4 & .00 & 3.38 & .74 \\
\hline Dinámica de las actividades & 3.43 & .53 & 3.60 & .24 & 3.86 & .38 & 3.63 & .52 \\
\hline Actividades para casa & 3.14 & .69 & 3.40 & .40 & 3.57 & .53 & 3.38 & .52 \\
\hline Cambios en la vida familiar & 2 & .00 & 2 & .00 & 2 & .00 & 1.75 & .46 \\
\hline $\begin{array}{l}\text { Mirada diferente a las } \\
\text { relaciones de familia }\end{array}$ & 1.43 & .79 & 2 & .00 & 2 & .00 & 2 & .00 \\
\hline Reparto de responsabilidades & 1.57 & .79 & 1.80 & .20 & 1.86 & .38 & 1.63 & .52 \\
\hline Expectativas a largo plazo & 2 & .00 & 2 & .00 & 1.71 & .76 & 1.88 & .35 \\
\hline $\begin{array}{l}\text { I. Prueba de Kruskal-Wallis }\left(\chi^{2}=7.43 ;\right. \\
\text { P }=0.06)\end{array}$ & & & & & & &
\end{tabular}

Todos los participantes, media igual a 2 y desviación típica igual a cero, han considerado que la secuenciación de las sesiones ha sido coherente y fácilmente comprensible.

En la percepción sobre si los contenidos trabajados han sido provechos para su vida familiar, se ha encontrado una ligera diferencia entre los centros $\left(\chi^{2}=7.43 ; p=0.06\right)$. En uno de ellos han considerado que los contenidos del programa siempre han resultado provechosos. En los otros tres han situado esta respuesta entre casi siempre (valor 3) y siempre (valor 4). Los contenidos que consideran más importantes han sido: en primer lugar, los temas de "cuidar la comunicación" (se abordan los mensajes "yo" y la escucha activa); en segundo lugar, la solución negociada de los conflictos en el caso del reparto de tareas domésticas; y, por último, los modos de educar (estilos educativos) y el establecimiento de límites y normas en familia. Es cierto que dichas temáticas son aspectos muy importantes en la tarea educativa y en las que las familias precisan

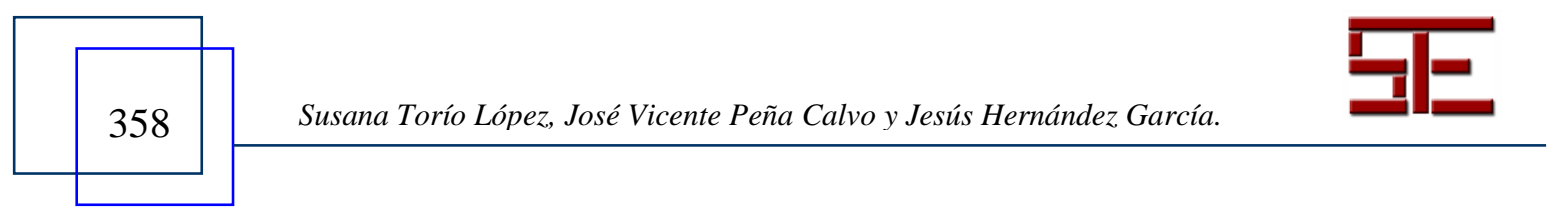




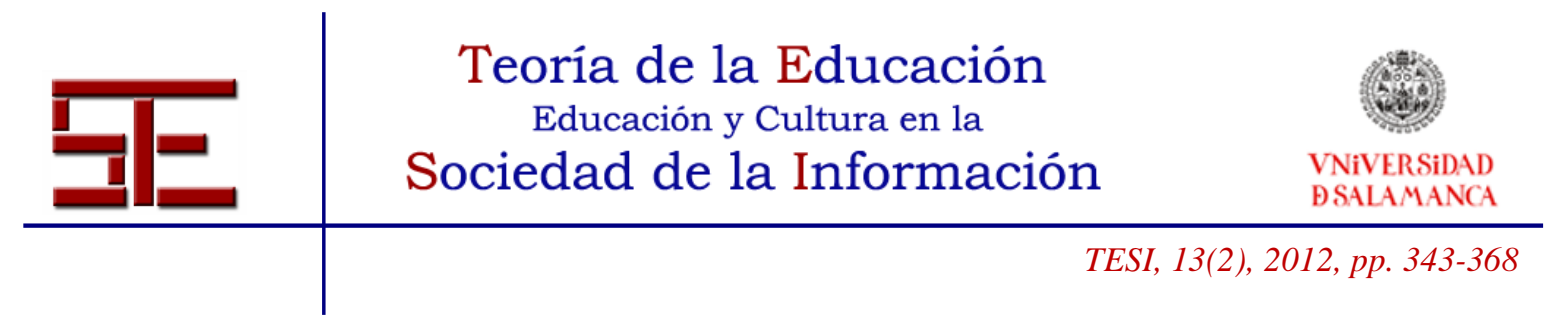

asesoramiento. En la convivencia familiar surgen inevitablemente comportamientos en alguno de sus miembros (pareja, hijos e hijas...) que contribuyen a que se sientan descontentos, frustrados, molestos, etc. La comunicación es la base de un buen clima familiar.

Los participantes han valorado entre "casi siempre" y "siempre" el grado de aprovechamiento de las dinámicas realizadas en las sesiones, para su vida familiar. Se han destacado aquellas actividades relacionadas con la comunicación y resolución de los conflictos (rol-playing y estudio de casos). También, aspectos relacionados con los estilos educativos (cumplimentar un cuestionario a fin de conocer su tendencia de comportamiento en las prácticas educativas con sus hijos e hijas, el ejercicio de establecimiento de normas, etc.). Sin duda, lo más interesante para las madres y padres, y así es constatado en los diarios de los educadores y educadoras, en los cuestionarios de fin de sesión y en diálogos mantenidos con los participantes, es la posibilidad de "intercambiar experiencias", de "dialogar entre los padres y madres", la puesta en común de los temas y el debate", "las perspectivas de los padres ante un mismo problema", etc.

Del mismo modo han sido evaluadas las actividades que tenían que realizar en casa los dos miembros de la pareja ("casi siempre" y "siempre"). En sus palabras: "El padre y yo hablamos en común", "Aprender a comunicarme con mensajes yo", "Diálogo con la pareja para resolver los problemas", "Negociar con los hijos", "Me han parecido, en algunos casos, complicadas para trasladar las experiencias familiares al papel", "Darse cuenta de que nuestros problemas son menos raros de lo que nos parece", entre otras.

La mayor parte de los participantes han considerado que gracias al programa se han producido cambios de interés en su vida familiar (media igual a 2 y desviaciones típicas igual a cero en tres de los centros). En el centro 4, la media en esta pregunta ha sido superior a 1.50. En el intento de señalar al menos dos cambios, se indica que los principales logros han sido en aspectos relativos a la comunicación: "Intento de mejorar en el proceso de comunicación", "Me fijo más en la manera en que me comunico con mi hijo", "Estamos más dispuestos a comunicarnos tranquilamente. Intentamos guardar más la calma", "Soy más consciente de la necesidad de escuchar", "Más diálogo, menos desprecios", "Usamos más los mensajes que expresan nuestros sentimientos ante algo que nos moleste", "La comunicación con mi pareja e hija", etc. También, en aspectos relativos a la resolución de los conflictos y su negociación: "Enfocar los conflictos de forma diferente", "No reñir tanto y más negociar", "Resolver los conflictos. Tener más

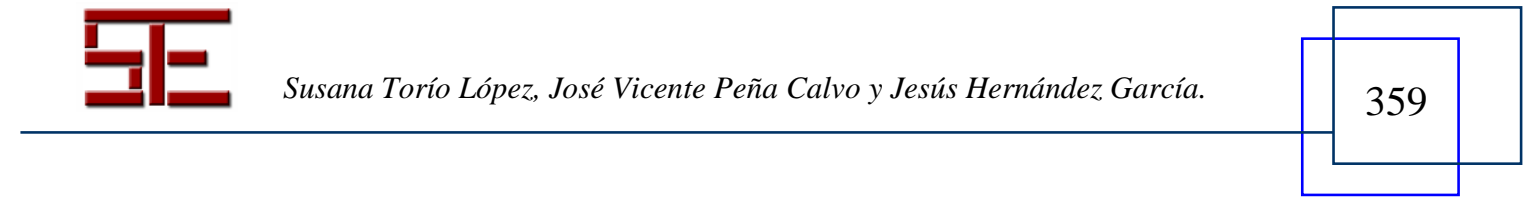




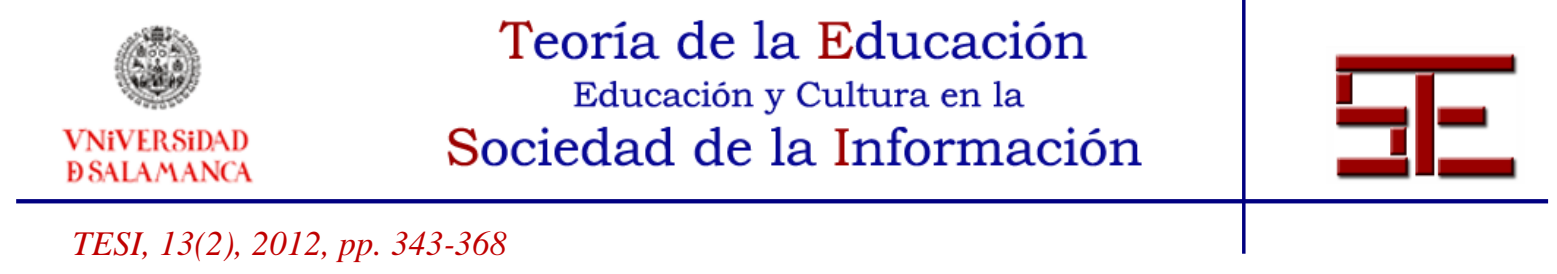

paciencia con los hijos", "Enfocar los conflictos de forma diferente". Además, como venimos comentando, el tema de las normas es de gran interés y se han producido cambios en la vida cotidiana: "Entiendo la importancia de establecer normas claras", "Mi firmeza en el comunicación de la norma", "Establecemos normas con mayor coherencia"; en síntesis, "Más sensación de que hacemos bien nuestro trabajo como padres". Finalmente, se constatan cambios en el reparto del trabajo doméstico: "Mejora en el trabajo doméstico", "Participación de los hijos en las tareas domésticas", "Más colaboración", "Mejor comprensión del reparto de tareas domésticas", "Hemos hecho más hincapié en las tareas de nuestros hijos en la casa".

Sin duda, el cambio no es fácil, es un proceso costoso y requiere esfuerzo y tiempo. Pero ¿qué obstáculos nos encontramos a la hora de iniciar procesos de cambio?: "la paciencia", "el estado de ánimo (a veces no hay tiempo, prisa, decides esperar o iniciar otro día...)", "el autocontrol", "los hábitos (nos cuesta romper con lo que venimos haciendo siempre, formas de ser, carácter)", "cosmovisiones diferentes: yo lo quiero cambiar y él no", ponerse en el lugar del otro", "la pereza y el cansancio...".

En tres de los centros, todos sus participantes dicen que, gracias al programa, han aprendido a mirar las relaciones familiares de otro modo (media igual a 2 y desviación típica igual a cero). En un cuarto centro se ha obtenido una media por debajo de la respuesta afirmativa (colegio 1). Podemos señalar: "Tengo ahora más herramientas y pautas para conseguir nuestro objetivo", "Me fijo más en el modo en que resuelvo o intento resolver los conflictos", "Me siento más segura y reconfortada por la experiencia similar de otros padres", "Ya no me siento un bicho raro. Tengo mi pequeña familia y no se diferencia tanto de los demás", "He perdido un poco el miedo a la existencia de conflictos", "Pienso en la posición de los demás miembros", "Dedicar más tiempo al diálogo", "Me doy cuenta de que el que yo vea un problema o sepa realizar alguna tarea del hogar, no quiere decir que los demás lo sepan", "Me ha ayudado ha identificar algunos puntos débiles y las oportunidades de mejora correspondientes".

En el reparto de responsabilidades, la media de los participantes ha señalado que el programa ha considerado mejorar en este aspecto en un 50\% de las familias (la mediana en esta variable ha sido de 2, y la media se encuentra en todos los casos por encima de 1.50). Las madres y padres nos comentan: "Nos hemos parado a pensar si el reparto era justo y equitativo y hemos introducido algunos cambios", "Colaboramos todos", etc. La participación de las hijas e hijos en el trabajo doméstico se ha visto reforzado y es comentado por muchas familias: "Los críos colaboran más y tienen más tareas",

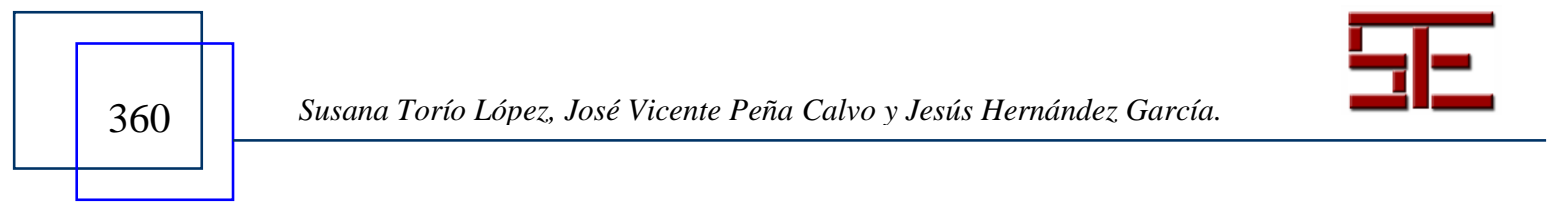




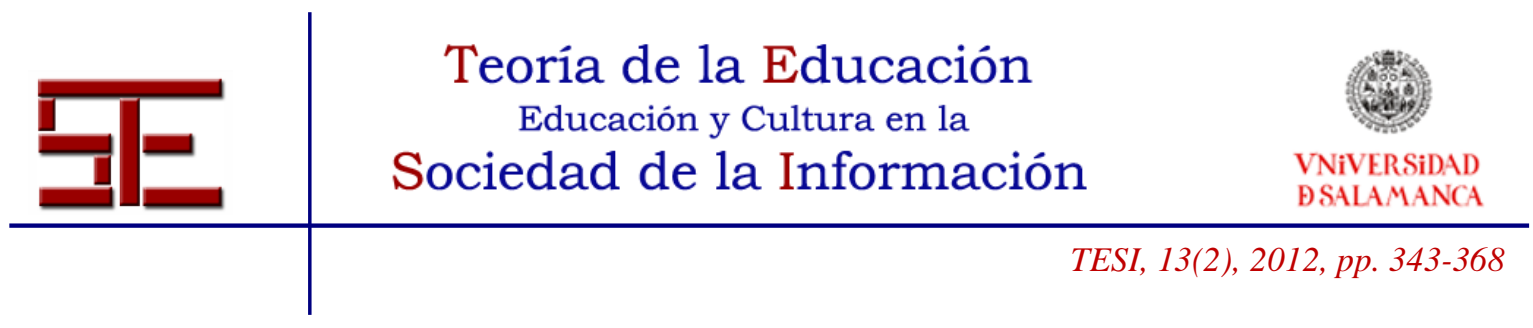

"Somos más conscientes de las razones que hemos utilizado para repartir las tareas y de lo que podemos encomendar a nuestra hija", "Implicamos más a nuestra hija", "Estaba ya bien, pero sí hemos sido más conscientes de que hay que poner más tareas a los niños", "En nuestro caso, el reparto de responsabilidades no era el mayor problema, pero ahora sé cómo afrontarlo de cara al futuro cuando crezca la niña". Las madres han constatado el interés por que su pareja colabore más: "Que él hace más cosas en comparativa", "Espero que mi marido se haya dado cuenta de lo que conllevan las tareas del hogar y de lo que a mí me afecta", "Lo de sobrevalorar el trabajo del marido ha quedado en evidencia...". Uno de los objetivos centrales del programa es poner en marcha procesos de socialización (educación familiar) para que en el seno de los grupos de trabajo se produzcan cambios de los esquemas mentales estereotipados de género en materia de corresponsabilidad y se constituyan unos esquemas nuevos libres de estereotipos.

En general la mayoría de las familias tienen expectativas positivas a largo plazo sobre la estabilidad en los cambios conseguidos con el programa. Como se puede ver en la Tabla 6, en dos colegios todas las personas han respondido afirmativamente a esta pregunta (media igual a 2 y desviación típica igual a cero), en los otros dos centros las medias están por encima de 1.50. En este aspecto, una herramienta que han valorado de interés han sido las guías de madres y padres que se han repartido al final de cada sesión. Sus opiniones nos transmiten el interés de seguir transfiriendo los conocimientos aprendidos a la vida cotidiana y la posibilidad de recurrir a dichas guías en caso de necesidad. Han comentado que son de gran utilidad: "como recordatorio", "para repasar los contenidos expuestos" o "para asentar lo oído en cada sesión y sobre todo para repasar en el futuro y recordar lo aprendido". También señalan: "Tengo que confesar que todavía no las he leído con detenimiento, pero me gusta saber que las tengo allí para poder recurrir a ellas", "Son concretas, claras y útiles. De vez en cuando las leo", "Las he leído todas y están bien como resumen de las clases", "Son de gran ayuda para consultar de vez en cuando", etc.

Finalmente, reflejamos algunas opiniones ofrecidas por los padres y madres en la valoración general del programa que nos han parecido reveladoras e interesantes y en las que se aprecia que se sienten escuchados y comprendidos, que se crean lazos de amistad entre las personas participantes, y se disminuye el sentimiento de culpa que tienen muchos padres al constatar que otros tienen las mismas inquietudes e, incluso, problemáticas. Además, es valorada como muy interesante la presencia de ambos miembros de la pareja (salvo en el caso de familias monoparentales), condición a la que

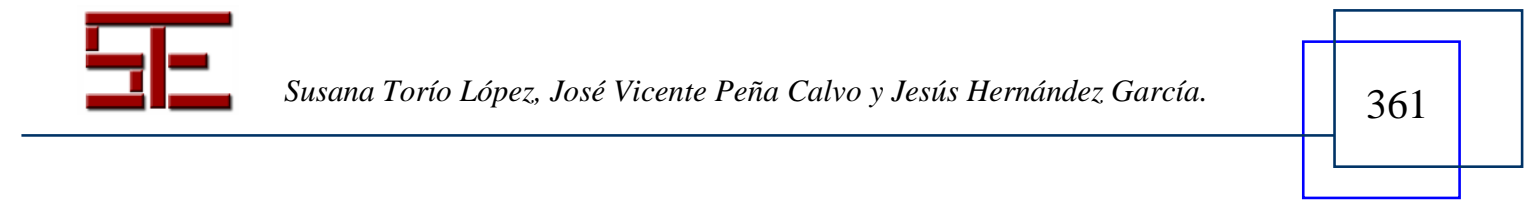




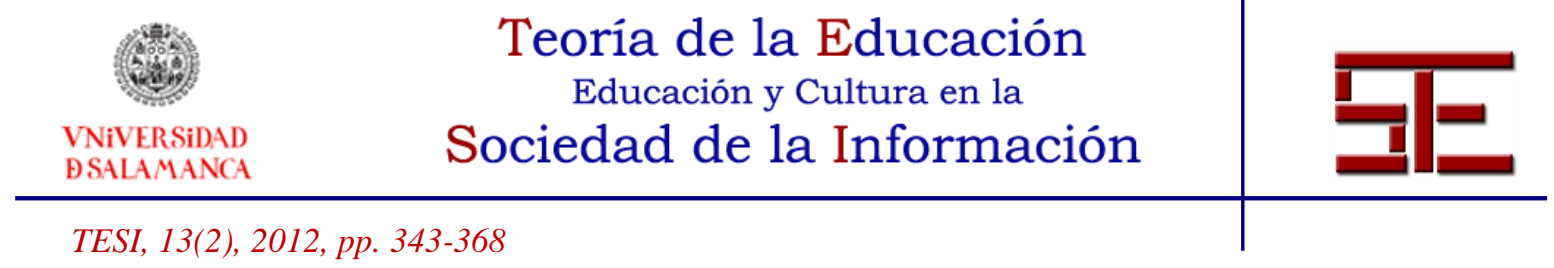

no hemos renunciado en la captación de familias, ya que es fundamental para provocar cambios en la dinámica familiar y más, si cabe, en la temática que nos ocupa (ver Tabla 7).

Tabla 7. Valoración general del programa

\begin{tabular}{|c|c|c|}
\hline $\begin{array}{lcll}\text { Me } & \text { ha } & \text { gustado } & \text { del } \\
\text { programa... } & & \end{array}$ & Cambiaría del programa.... & $\begin{array}{l}\text { ¿Recomendaría a otros padres y } \\
\text { madres su participación en el } \\
\text { programa? ¿Por qué? }\end{array}$ \\
\hline $\begin{array}{l}\text { "Intercambio de experiencias } \\
\text { con otros padres". }\end{array}$ & $\begin{array}{l}\text { "Me gustaría que abarcara más } \\
\text { temas y tuviera más duración". }\end{array}$ & $\begin{array}{l}\text { "Sí. Aporta visiones nuevas y } \\
\text { muy interesantes acerca de algo } \\
\text { que a priori nos parece que más o } \\
\text { menos podemos tener controlado. } \\
\text { Te abre los ojos..." }\end{array}$ \\
\hline $\begin{array}{l}\text { "Sí, aunque es mi primera } \\
\text { experiencia y no puedo } \\
\text { comparar con otro, pero el } \\
\text { hecho de que haya hecho el } \\
\text { esfuerzo de asistir a todas las } \\
\text { sesiones y me haya animado a } \\
\text { participar activamente en todas } \\
\text { las actividades me parece que } \\
\text { puede ser valorable, así como el } \\
\text { que me haya sentido cómoda a } \\
\text { la hora de expresar mis ideas". }\end{array}$ & $\begin{array}{l}\text { "En general estaba muy bien...tal } \\
\text { vez quitaría más elementos de } \\
\text { lección magistral... no sé si es } \\
\text { posible, ya que también hay que } \\
\text { dar contenidos, pero lo que mejor } \\
\text { resultó eran las sesiones en las } \\
\text { que los padres hablaban/actuaban } \\
\text { lo más..." }\end{array}$ & $\begin{array}{l}\text { "Creo que es una oferta } \\
\text { estupenda... lo recomiendo a todo } \\
\text { el mundo. No hace falta tener } \\
\text { grandes problemas, siempre hay } \\
\text { algo y siempre nos hace falta } \\
\text { reforzarnos juntos con otras } \\
\text { personas... creo que algo así } \\
\text { debería ser obligatorio... creo que } \\
\text { también es importante que sea } \\
\text { obligatorio la asistencia de padre } \\
\text { y madre (si los hay) para evitar } \\
\text { que solo se encarguen las } \\
\text { madres..." }\end{array}$ \\
\hline $\begin{array}{l}\text { "Sí, sí, muchísimo, los que no } \\
\text { vinieron no saben lo que se } \\
\text { perdieron, ¡de verdad!”. }\end{array}$ & $\begin{array}{l}\text { "Les daría un poco más de } \\
\text { tiempo para que nos pudieran } \\
\text { enseñar más cosas". }\end{array}$ & $\begin{array}{l}\text { "Sin duda. Hay veces que no } \\
\text { sabes lo interesante que es un } \\
\text { programa hasta que participas en } \\
\text { él". }\end{array}$ \\
\hline $\begin{array}{l}\text { "La participación de las parejas } \\
\text { y ver que todos pecamos casi de } \\
\text { lo mismo". }\end{array}$ & "No. Repetiría el próximo curso" & $\begin{array}{l}\text { "Sí, porque nos hicimos amigos } \\
\text { un grupo de gente que no se } \\
\text { conocía". }\end{array}$ \\
\hline $\begin{array}{l}\text { "Me gustó mucho la forma en } \\
\text { que lo llevaron las educadoras } \\
\text { del grupo. Estaban muy } \\
\text { preparadas y fomentaron el } \\
\text { trato cercano y confidencial que } \\
\text { tuvimos en el grupo. Me gustó } \\
\text { mucho la cercanía que se } \\
\text { produjo entre los miembros del } \\
\text { grupo, la complicidad, la } \\
\text { sensación de que otros tenían } \\
\text { problemas parecidos... el }\end{array}$ & $\begin{array}{l}\text { "No, está todo genial: genial la } \\
\text { dinámica, genial el contenido, } \\
\text { genial las prácticas". }\end{array}$ & $\begin{array}{l}\text { "Sí. Aprendes no solo temario, } \\
\text { también práctica. Sobre todo en } \\
\text { las puestas en común de los casos. } \\
\text { Aprendes de la experiencia de } \\
\text { otras personas. También sentir } \\
\text { que las cosas no sólo te pasan a } \\
\text { ti". }\end{array}$ \\
\hline
\end{tabular}

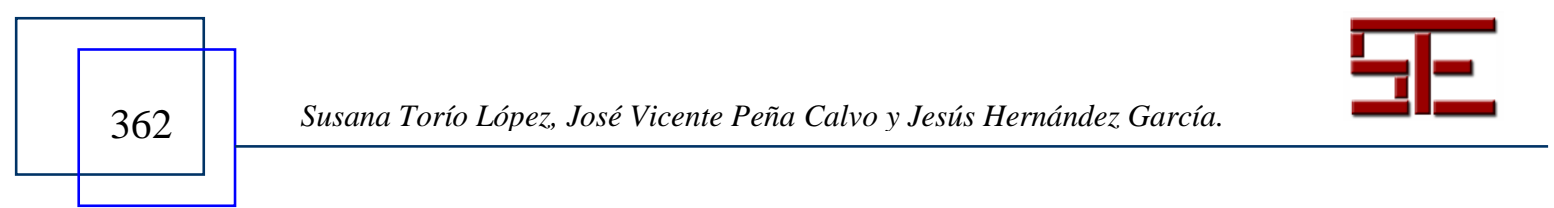




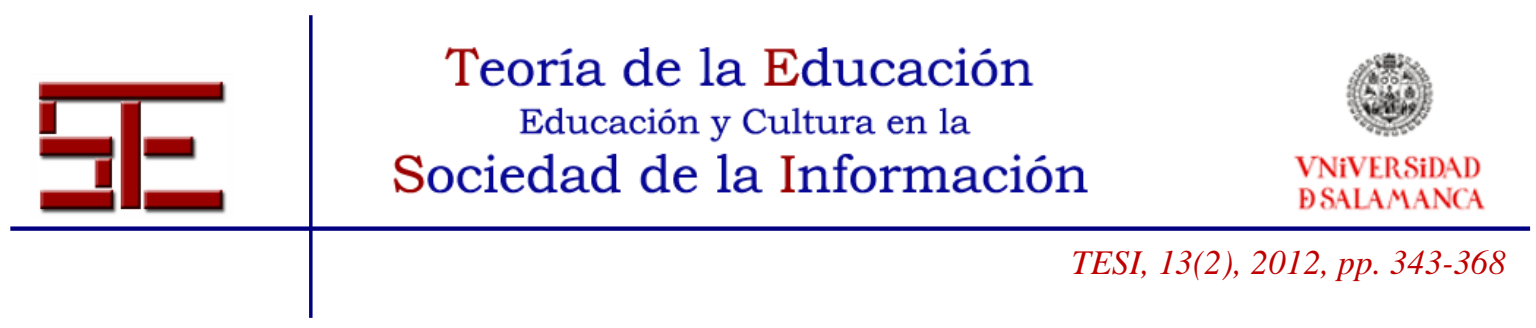

\begin{tabular}{|l|l|l|}
\hline $\begin{array}{l}\text { ambiente de honestidad y de } \\
\text { compartir cosas a menudo } \\
\text { difíciles nos unía. Voy a echar } \\
\text { de menos a todos". }\end{array}$ & \\
\hline $\begin{array}{l}\text { "No solo es exponer las cosas } \\
\text { técnicas. Da participación a las } \\
\text { parejas exponiendo sus casos". }\end{array}$ & $\begin{array}{l}\text { "Quizás el tiempo y un par de } \\
\text { familias más". }\end{array}$ & $\begin{array}{l}\text { "Sí, porque les daría una visión } \\
\text { más amplia de la realidad familiar } \\
\text { y cotidiana". }\end{array}$ \\
\hline $\begin{array}{l}\text { "Que vienen los dos miembros } \\
\text { cosas tareja, para mejorar las que verlo ambas } \\
\text { partes". }\end{array}$ & $\begin{array}{l}\text { participativo...". } \\
\text { "Rotundamente. No se aprende a } \\
\text { educar por ciencia infusa. Hoy en } \\
\text { día es necesario conocer ciertas } \\
\text { pautas y herramientas } \\
\text { para } \\
\text { solucionar conflictos y situaciones } \\
\text { que aparecen en el día a día de las } \\
\text { familias". }\end{array}$ \\
\hline
\end{tabular}

\section{4.- CONCLUSIONES}

La finalidad fundamental de la evaluación final de un programa es la constatación del grado de eficacia alcanzado (Pérez Juste, 2006, 247), esto es, del nivel de logro conseguido en los diversos objetivos a los que sirve el programa. Hemos obtenido información útil en cuanto a aspectos positivos del programa (contenidos, dinámicas, materiales, participación...). Podemos decir que la aplicación del programa ha tenido una buena acogida y aceptación por parte de las madres y padres participantes y les ha aportado aprendizajes útiles que han logrado transferir a su vida diaria, su cotidianeidad. Valoran tanto los aspectos formales del programa (contenidos, metodología, actividades, recursos...) como los aspectos relacionales generados en las dinámicas de las sesiones de trabajo. Se han producido cambios, a corto plazo, en las cogniciones y en los comportamientos de los participantes. La "formación de padres" indica un intento de acción formal con el objeto de incrementar la conciencia de las madres y los padres y la utilización de sus aptitudes y competencias parentales (Lamb y Lamb, 1978; Brock, Oertwein \& Coufal, 1993). Para Cataldo (1991:17), "forma parte de la educación de los niños y es un método para ayudarles a crecer y a desarrollarse. (...) les ayudan a obtener información y conocimientos para hacer que la educación de sus hijos sea más satisfactoria y eficaz”. De manera general, se trata de toda acción educativa de sensibilización, de aprendizaje, de adiestramiento o de clarificación de los valores, las actitudes y las prácticas de las madres y los padres en educación (Boutin y Durning, 1997; Brock, Oertwein \& Coufal, 1993). Las madres y padres participantes del programa han iniciado un proceso de cambio en su dinámica familiar, así como han reafirmado aspectos de su tarea educativa.

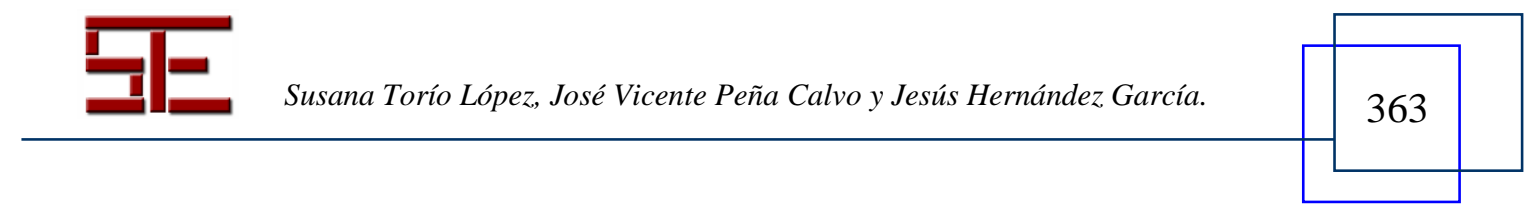




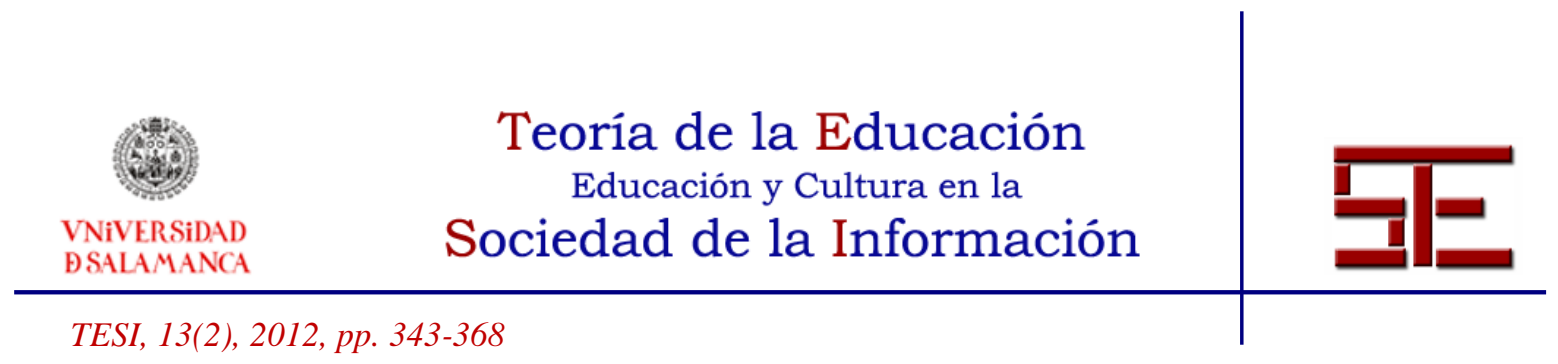

Si bien la realización e implementación de programas de educación familiar de otras temáticas está ampliamente difundida y son muy variadas las modalidades ofertadas (talleres, cursos, charlas, sesiones de orientación, etc.), los esfuerzos son menores en materia de evaluación de los mismos. Respecto a la eficacia de los programas de formación de madres y padres en materia de corresponsabilidad, las evaluaciones realizadas (Vila, 1998, 507) muestran que, mientras las madres y los padres participan en el programa, aumenta la estimulación hacia sus hijos e hijas y se consigue una mejor calidad de las interacciones. Sin embargo, también se observa que, con el paso del tiempo, dichos efectos desaparecen, excepto en aquellos casos en que las propias familias han estado involucradas en el diseño y en la elaboración de las actividades que configuran el programa. En el caso que nos ocupa, sin su presencia activa y responsable no tendría sentido el programa.

El programa incide positivamente en aspectos de las siguientes dimensiones:

- Con respecto a los modos de educar en familia, los padres y madres son más capaces de analizar el lugar que ocupa la maternidad y la paternidad en su proyecto de vida. Están más preparados para identificar cuáles son las estrategias y mecanismos de socialización familiar que pueden emplear en sus prácticas educativas con sus hijos e hijas. Manifiestan mayor capacidad para el establecimiento de normas y las consecuencias de su incumplimiento. La concepción de los padres y madres del ambiente familiar se torna más "autoritativa" posibilitando la implicación de todos los miembros de la familia en la toma de decisiones. En síntesis, se ha reforzado el sentimiento de seguridad y competencia de las madres y padres en su tarea educativa.

- Referente al trabajo doméstico y sus categorías básicas (tareas del hogar, cuidado de los hijos e hijas y trabajo emocional), después del programa, los padres y madres son más conscientes de la necesidad de llegar a un reparto más justo e igualitario y a profundizar en el conjunto de tareas que se incluyen en el mismo. Han manifestado ambas partes de la pareja sus inquietudes y vivencias en relación al reparto, iniciando, en muchos casos, una reestructuración del mismo. Sin duda, se han conseguido estrategias para conseguir la participación de los hijos e hijas en las tareas domésticas y adquirido las nociones básicas acerca de las ventajas o potencialidades educativas que supone en el desarrollo individual y social de los menores su participación en las responsabilidades familiares.

- Finalmente, se ha dotado de herramientas para establecer una relación familiar más satisfactoria y lograr cambios en la dinámica familiar. Son conscientes de los

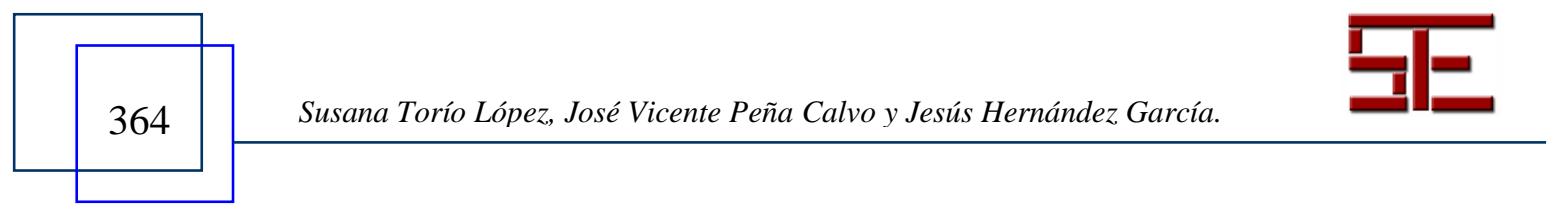




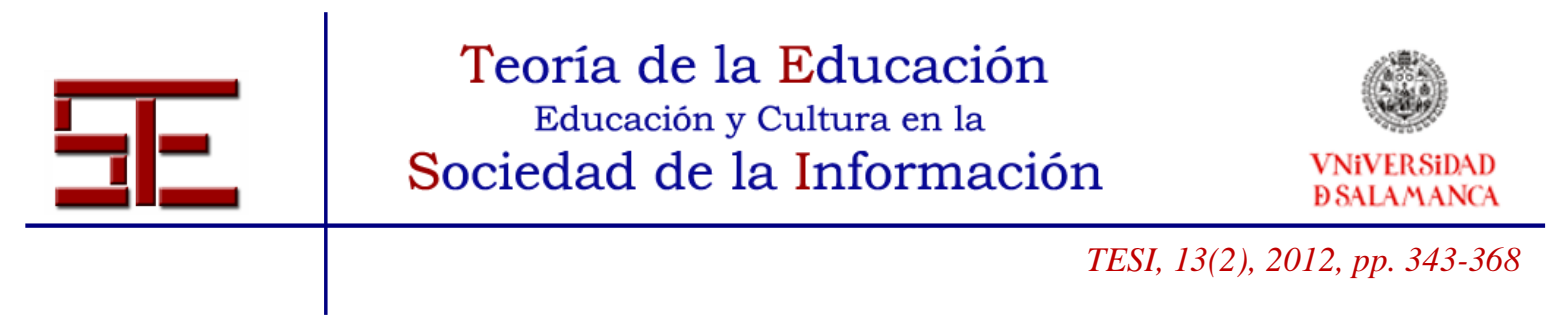

conflictos provocados por las diferencias que manifiestan hombres y mujeres cuando ejecutan las labores del hogar (por ejemplo, la escasa participación masculina o por las dificultades que tienen algunas mujeres de delegar responsabilidades con respecto al trabajo doméstico, en especial las relativas al cuidado infantil). Se ha visto la necesidad de modificar los patrones de comunicación por otros más adecuados (mensajes "yo", escucha activa y mostrar aceptación) y lo intentan. El tema de las habilidades comunicativas es elemento básico en otros programas de educación parental (Dinkmeyer, 1976; Gordon, 2006; Maganto \& Bartau, 2004; Martínez González, 2009). De igual modo, son más proclives a afrontar los conflictos sobre el reparto del trabajo familiar desde la negación y la cooperación.

Junto con los logros y aciertos, la evaluación nos ha servido de base para introducir modificaciones en una sucesiva aplicación así como la identificación de aspectos susceptibles de mejora respecto a aspectos formales del programa (revisión de actividades, incorporación de materiales). Algunas limitaciones de los programas de formación de padres y madres (Martínez \& Pérez, 2004, 100-101) son compartidas pero, también, en nuestro caso, se han superado otras, como, por ejemplo, se puede apreciar a continuación en los siguientes aspectos:

- Sólo un número reducido de padres y madres pueden participar en el programa debido a la metodología activa y participativa. En nuestro caso, al asistir ambos miembros de la pareja (salvo en el caso de familias monoparentales), hemos constatado la necesidad de no superar las 10 personas, ya que se hace difícil la fluidez de las sesiones, así como la participación y la dinámica de todos los miembros.

- No siempre aquellos padres o madres que participan son quienes más necesitan desarrollar las habilidades que se proponen. No obstante, como se ha observado en sus propias palabras, no sólo es necesario mejorar o conocer para mejorar, sino también sentirse reforzados en lo que ya están realizando.

- Participan muy pocos varones. En nuestro programa es condición indispensable. Tanto es así, que se ha tenido que rechazar a varias personas que pretendían asistir sin que asistiera el otro miembro de la pareja.

- Algunos padres o madres pueden encontrar difícil exponer y expresar sus propias experiencias personales y familiares. En nuestro programa, por el contrario, se ha comprobado que el intercambio, el diálogo compartido, la comunicación, etc., han sido muy valorados. Se ha podido ofrecer, así, un

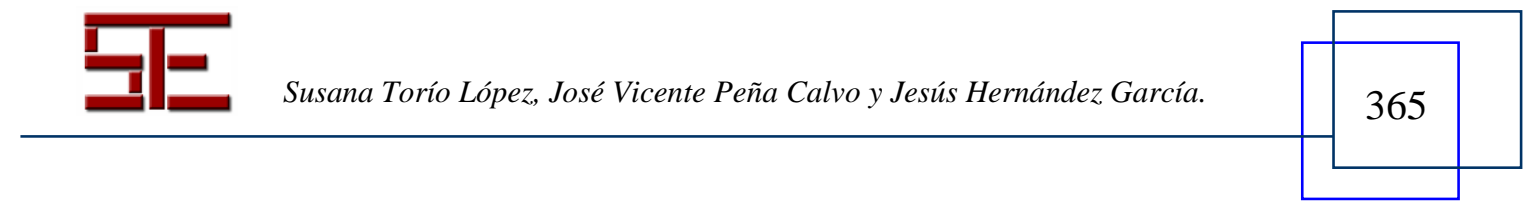




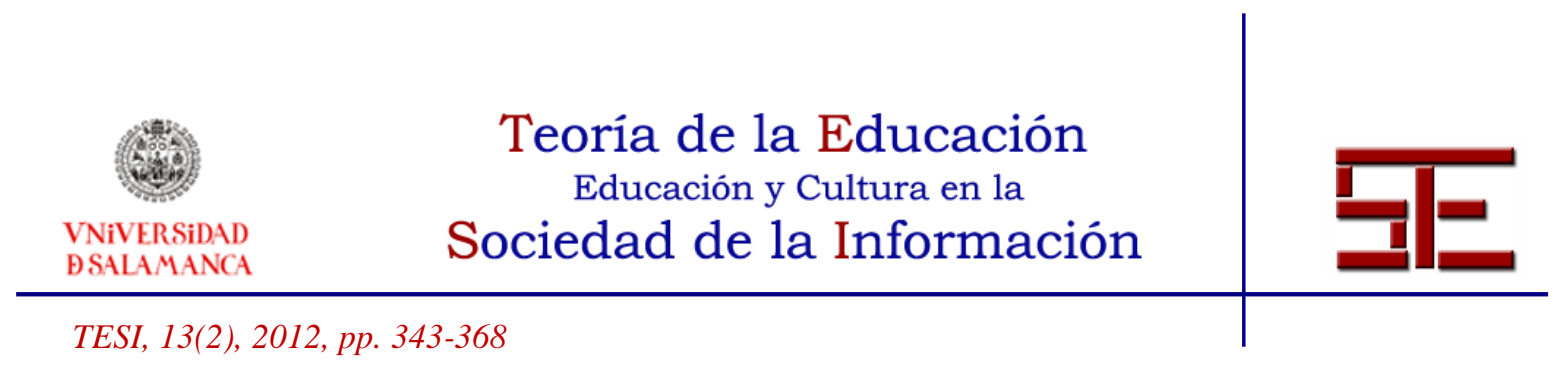

espacio que ha facilitado la expresión de sus preocupaciones y vivencias sobre la crianza y la educación de sus hijos e hijas.

- Con frecuencia esperan respuestas rápidas a sus problemas y "recetas" de conducta. En nuestro caso, también ha podido ocurrir así, pero al final se han dado cuenta de que no era ésa ni la finalidad ni lo más relevante del programa.

- Algunos padres y madres pueden desarrollar cierta dependencia hacia el coordinador o la coordinadora. En nuestro caso, al menos de forma feaciente y comprobada, y más allá de lazos de amistad, no ha ocurrido así.

- En ocasiones les falta paciencia y voluntad para modificar sus hábitos de conducta. Nuestro programa ha puesto realmente de manifiesto todo lo contrario.

- Algunos padres y madres pueden sentirse más insatisfechos después de concluir el programa por ser más conscientes de posibles "errores" de conducta. En nuestro caso, no habido frustración alguna, si bien sí conciencia de poder mejorar en muchos aspectos.

Estas conclusiones nos alientan a seguir trabajando en el tema, con más ahínco cuando, frente a la pérdida de interés (índice de desgaste) por parte de padres y madres y el abandono del programa con el paso de las sesiones, en nuestro caso, el índice de fidelidad y seguimiento a partir de la segunda sesión ha sido absoluto. Y nos anima también a "hacer visible" en mayor grado la responsabilidad y necesidad de un reparto más equilibrado del trabajo doméstico entre todos los miembros de la unidad familiar, pues los cambios son lentos y limitados. Sólo la corresponsabilidad real y efectiva en todas las partes permitirá avanzar hacia un modelo de vida más igualitario en el que se garantice el desarrollo personal, familiar y social de todos y todas.

\section{5.- BIBLIOGRAFÍA}

Alvira Martín, F. (1991). Metodología de la evaluación de programas. Cuadernos metodológicos. Madrid: CIS.

Boutin, G. \& Durning, P. (1997). Intervenciones socioeducativas en el medio familiar. Madrid: Narcea.

Brock, G. W., Oertwein, M. \& Coufal, J. D. (1993). Parent Education: Theory, research and practice. En M. E. Arcus, J. D. Schvaneveldt \& J. J. Moss (Eds.), Handbook of

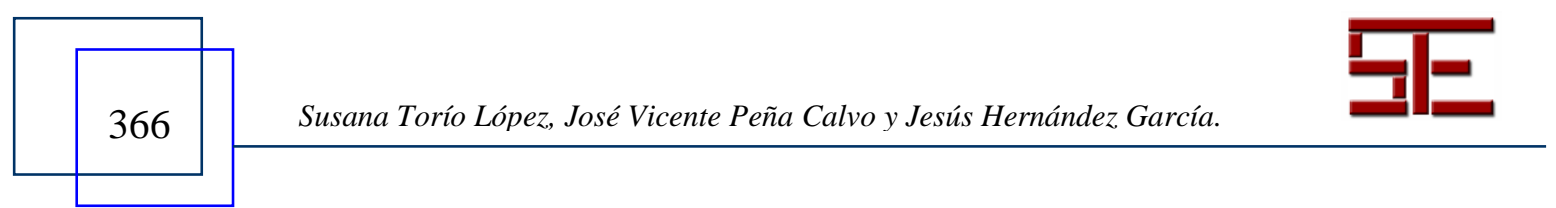




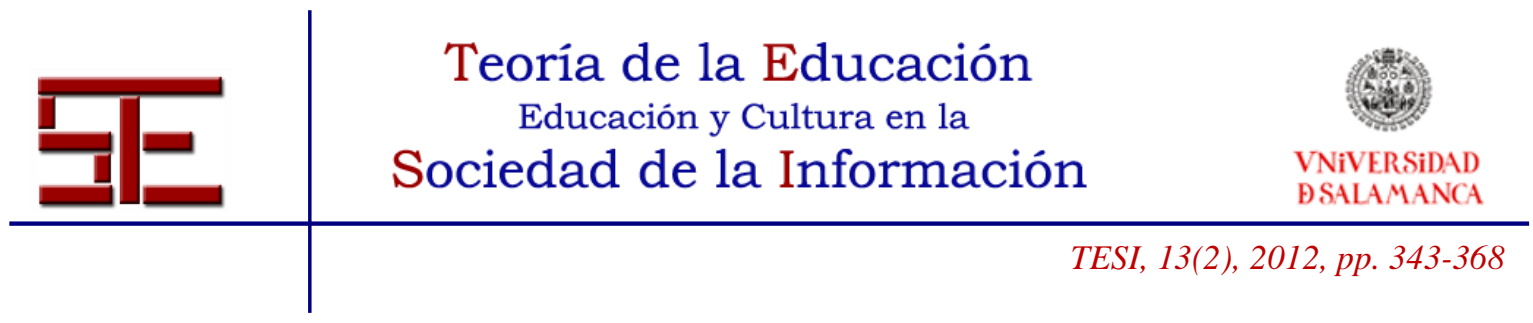

Family Life Education. The practice of Family Life Education, vol 2 (pp. 87-114). Newbury Park: Sage.

Cataldo, C.Z. (1991). Aprendiendo a ser padres: conceptos y contenidos para el diseño de programas de formación de padres. Madrid: Visor.

Dinkmeyer, D. \& McKay, G. D. (1976). Systematic Training for Effective Parenting: Parents Handbook. Minnesota: Ed. Cicle Pinner. American Guidance Services Inc. (Versión en castellano: Dinkmeyer, D. \& McKay, G. D. (1990). Padres eficaces con entrenamiento sistemático [P.E.C.E.S.]. Madrid: TEA.

Gordon, T. (2006). Técnicas eficaces para padres (TEP). Barcelona: Ediciones Medidi.

Hernández Fernández, J. \& Martínez Clares, P. (1996). Propuesta metodológica para evaluar programas de orientación educativa. Revista Electrónica de Investigación y Evaluación Educativa, 2 (2) 1-17.

Lamb, J. \& Lamb, W. (1978). Parent education and elementary counseling. New Cork: Human Sciences Press.

Maganto, J. M. \& Bartau Rojas, I. (2004). Programa COFAMI. Corresponsabilidad familiar. Fomentar la cooperación y responsabilidad de los hijos. Madrid: Pirámide.

Martínez González, R. A. (2009). Programa-Guía para el desarrollo de competencias emocionales, educativas y parentales. Madrid: Ministerio de Sanidad y Política Social.

Martínez González, R. A. \& Pérez Herrero, M ${ }^{a}$ H. (2004). Evaluación e intervención educativa en el campo familiar. Revista Española de Orientación Profesional (REOP), $15(1), 89-104$.

Municio, P. (1992). La evaluación segmentada de los programas. Bordón, 43 (4), 375395.

Pérez Juste, R. (1995). Evaluación de programas educativos. En A. Medina Rivilla \& L. M. Villar Angulo (Coords.), Evaluación de Programas educativos, centros y profesores (pp. 71-106). Madrid: Editorial Universitas.

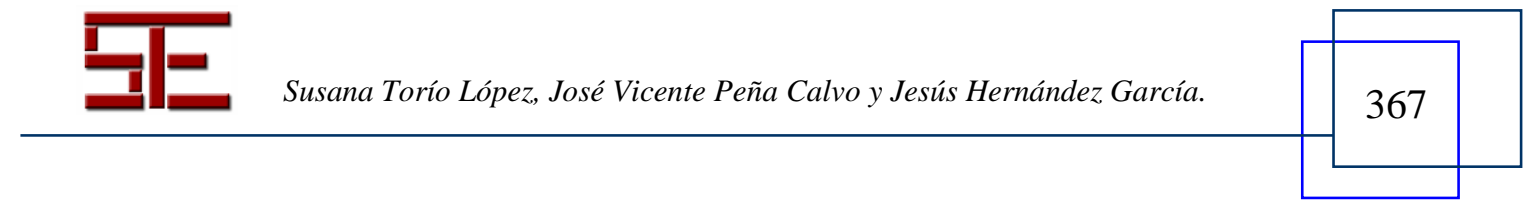




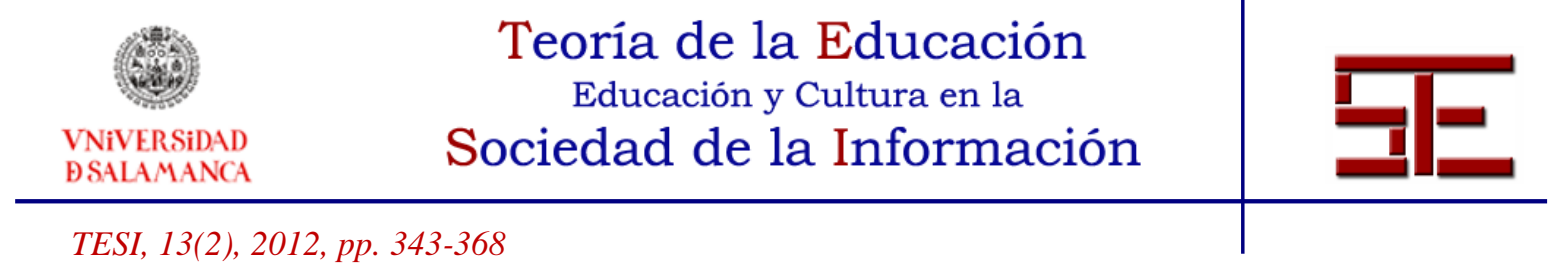

- (1996). La evaluación de programas educativos. En C. Martínez Mediano (Dir.), Evaluación de programas educativos. Investigación evaluativa. Modelos de evaluación de programas (pp. 223-236). Madrid: UNED.

- (2000). La evaluación de programas educativos: conceptos básicos, planteamientos generales y problemática. Revista de Investigación Educativa, 18 (2), 261-287.

- (2006). Evaluación de programas educativos. Madrid: La Muralla.

Sanz Oro, R. (1996). Evaluación de programas de orientación educativa. Madrid: Pirámide.

Tejedor, F. J. (2000). El diseño y los diseños en la evaluación de programas. Revista de Investigación Educativa, 18 (2), 319-339.

Torío López, S. (2011). Aplicación de un programa de Educación Parental "Construir lo cotidiano" para su validación: propuesta metodológica. En M $\mathrm{M}^{\mathrm{a}} \mathrm{R}$. Belando Montoso (Ed.), II Jornada monográfica "Pedagogía Social y Educación Social. Una mirada al futuro”(pp. 386-401). Madrid: Universidad Complutense.

Torío López, S., Peña Calvo, J. V., Rodríguez Menéndez, M. C., Fernández García, C. M. \& Molina Martín, S. (2010). Hacia la corresponsabilidad familiar: "Construir lo cotidiano. Un programa de educación parental”. Educatio Siglo XXI, 28 (1), 85-108.

Vila, I. (1998). Intervención psicopedagógica en el contexto familiar. En M $\mathrm{M}^{\mathrm{a}} \mathrm{J}$. Rodrigo \& J. Palacios (Coords.) Familia y desarrollo humano (pp. 501-519). Madrid: Alianza Editorial.

Para citar el presente artículo puede utilizar la siguiente referencia:

Torío López, S., Peña Calvo, J. V. y Hernández García, J. (2012). Primeros resultados de la aplicación y evaluación de un programa de educación parental: "Construir locotidiano". Revista Teoría de la Educación: Educación y Cultura en la Sociedad de la Información. 13(2), 343-368 [Fecha de consulta: dd/mm/aaaa].

http://campus.usal.es/ revistas_trabajo/index.php/revistatesi/article/view/9012/9256

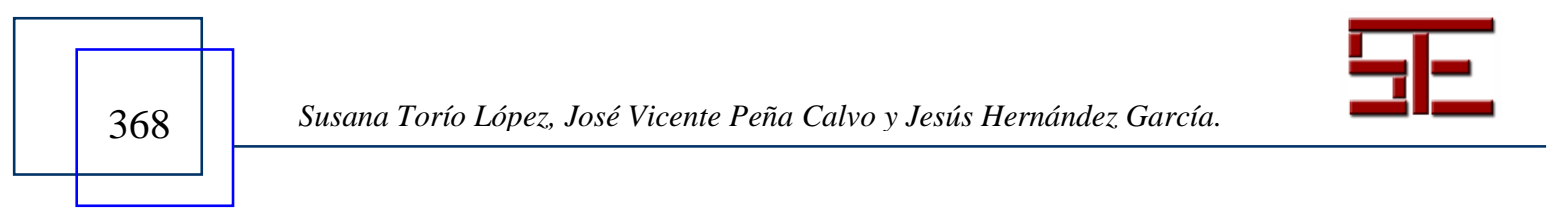

